\title{
Breakthrough in cardiac arrest: reports from the 4th Paris International Conference
}

Peter J. Kudenchuk ${ }^{1}$, Claudio Sandroni ${ }^{2}$, Hendrik R. Drinhaus ${ }^{3}$, Bernd W. Böttiger ${ }^{3}$, Alain Cariou ${ }^{4,5}$, Kjetil Sunde ${ }^{6}$, Martin Dworschak ${ }^{7}$, Fabio Silvio Taccone ${ }^{8}$, Nicolas Deye ${ }^{9}$, Hans Friberg $^{10}$, Steven Laureys ${ }^{11}$, Didier Ledoux ${ }^{12}$, Mauro Oddo ${ }^{13}$, Stéphane Legriel ${ }^{14}$, Philippe Hantson ${ }^{15}$, Jean-Luc Diehl ${ }^{16^{*}}$ and Pierre-Francois Laterre ${ }^{17}$

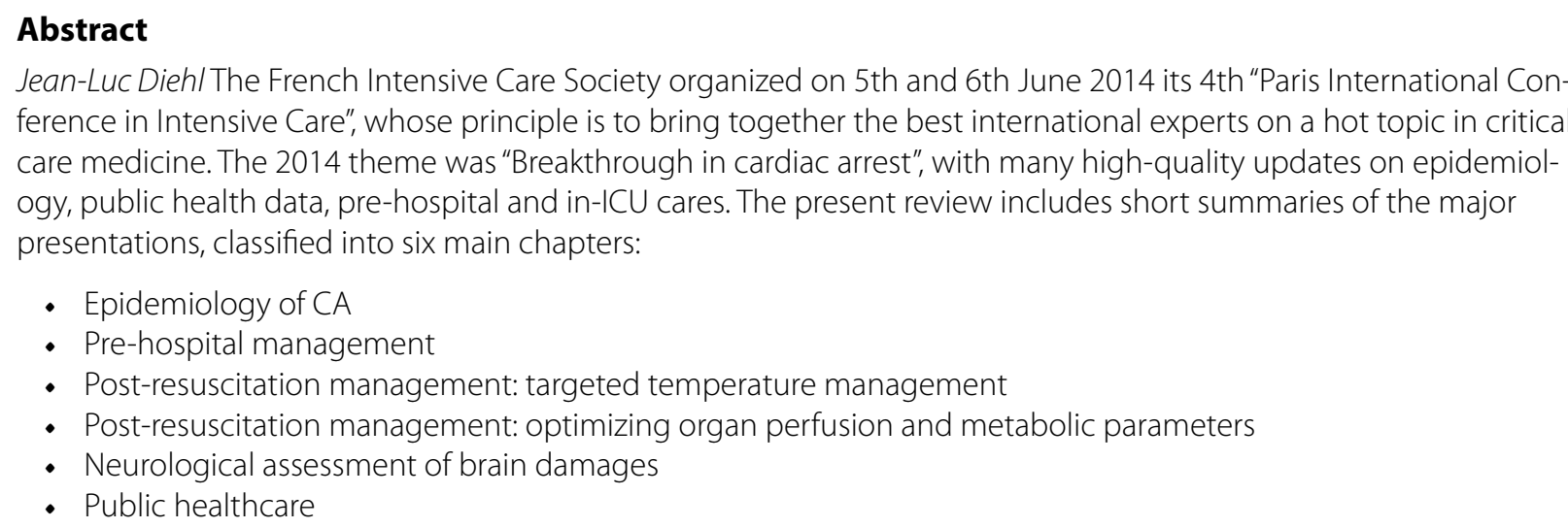

Keywords: Cardiac arrest, Cardio-pulmonary resuscitation, Targeted temperature management, Therapeutic hypothermia, Persistent vegetative state, Minimally conscious state, Organ donation

\section{Review \\ Epidemiology of CA \\ Out-of-hospital cardiac arrest in 2014: incidence, outcome and disparities}

Peter Kudenchuk Out-hospital-cardiac arrest (OHCA) remains a common public health problem. Each year, cardiac arrest claims more than 424,000 lives in the United States, 300,000 lives in Europe, and upwards of 3.7 million lives worldwide. Resuscitation is typically conducted in accordance with a uniform algorithmic approach embodied in the "chain of survival" which emphasizes the importance of early activation of emergency medical services, prompt CPR, rapid defibrillation, advanced cardiac life support and post-cardiac arrest care. This, in fact might be

\footnotetext{
*Correspondence: jldiehl@invivo.edu

${ }^{16}$ Medical Intensive Care Unit, AP-HP, European Georges Pompidou Hospital, Paris Descartes University and Sorbonne Paris Cité-Medical School, Paris, France

Full list of author information is available at the end of the article
}

said to be the only uniform aspect of cardiac arrest, which is otherwise riddled with disparities. The first of these disparities lies in how few patients who are successfully resuscitated from cardiac arrest ultimately survive to hospital discharge. In Seattle, approximately $60 \%$ of patients in whom cardiac arrest presents as ventricular fibrillation (VF) are successfully resuscitated and admitted to hospital; yet only about half of these (30\%) typically survive to hospital discharge. When cardiac arrest presents as asystole or pulseless electrical activity (PEA), outcomes are strikingly worse: only $20-30 \%$ of such patients are successfully resuscitated, and an even smaller proportion of these, as few as 2 in 10 -ranging from 2 to $5 \%$ of patients, survive to hospital discharge [1].

A second disparity lies in the changing incidence of rhythms that precipitate cardiac arrest. In Seattle during the decade of the 1970s, VF accounted for approximately $60 \%$ of all out-of-hospital cardiac arrests treated by emergency medical services (EMS), whereas the 
remainder of acute rhythm presentations were equally divided between asystole and PEA. In the ensuing years, the proportion of cardiac arrests caused by VF has declined to $25-30 \%$ of cases, such that now asystole and PEA represent the most common presenting rhythms. Extrapolating these incidence data from Seattle to the United States census, the annual rate of cardiac arrest due to ventricular fibrillation declined from about 85 persons per 100,000 in 1980 to $38 / 100,000$ in 2000 [1]. Data from the Resuscitation Outcomes Consortium estimated a further decline in the incidence of VF cardiac arrest to 17.4 adults/100,000 in 2011 [2]. These statistics, coupled with the known worse survival prognosis of patients in whom cardiac presents as a non-shockable rhythm, pose a new and major challenge for the present and future treatment of this emerging "new wave" of cardiac arrest victims.

A third disparity lies in the marked differences in outcome from cardiac arrest between communities across Europe and the United States. For cardiac arrest due to VF, survival can vary significantly between major cities by many-fold (Fig. 1) [3-5]. To some extent, such differences in outcome are explained by inaccuracies in record keeping. For example, few communities actually report their incidence of cardiac arrest and outcome [6]. And even among those that do, complete capture of all cases of cardiac arrest and the reliability of their survival data can be questionable, accounting for some of the variability in outcomes that are reported. This said, record keeping alone does not entirely explain these discrepancies. Identifying and targeting remediable causes of differences in survival between communities is imperative if we are to assure citizens that they are comparably "safe" from death by cardiac arrest in whatever locale they call home. Clinical factors that are known to account for differences in survival outcome from cardiac arrest include patient characteristics - such as age, gender, and co-morbidities; and by the circumstances of the arrest-such as whether witnessed by bystanders, the location of its occurrence, and by the presenting arrest rhythm. Most would regard these as "factors of fate" and as such not alterable. Conversely, the components of prehospital emergency medical care, including rapid dispatch, dispatcher-assisted CPR, EMS training and time-to-treatment, are all potentially correctable factors. Targeting these aspects of prehospital care affords an opportunity to change outcome for the better after cardiac arrest. Among these, perhaps the one that can be most readily and immediately implemented is high-performance CPR.

High-performance CPR consists of training with meticulous attention to the details of performing CPR to the best known prescribed parameters of chest compression rate, depth, full chest recoil, and minimized interruptions, and applying strict compliance standards (e.g. a compression fraction of no less than $85 \%$ ) for their performance during resuscitation. In addition to striving for "letter perfect" CPR performance, it also involves a system of accountability, whereby feed-back of CPR performance derived from a review of recordings of field resuscitations is consistently conveyed back to providers for further possible improvement. Deploying such a highperformance CPR protocol in King County, Washington, starting in 2005 resulted in a significant improvement in survival from both cardiac arrest due to ventricular fibrillation (Fig. 2) [7], as well as asystole/PEA [8] that has been sustained in the ensuing years. The attractiveness of high-performance CPR is that it is relatively inexpensive to deploy (can be easily added to existing EMS training programs), does not require special equipment (hands
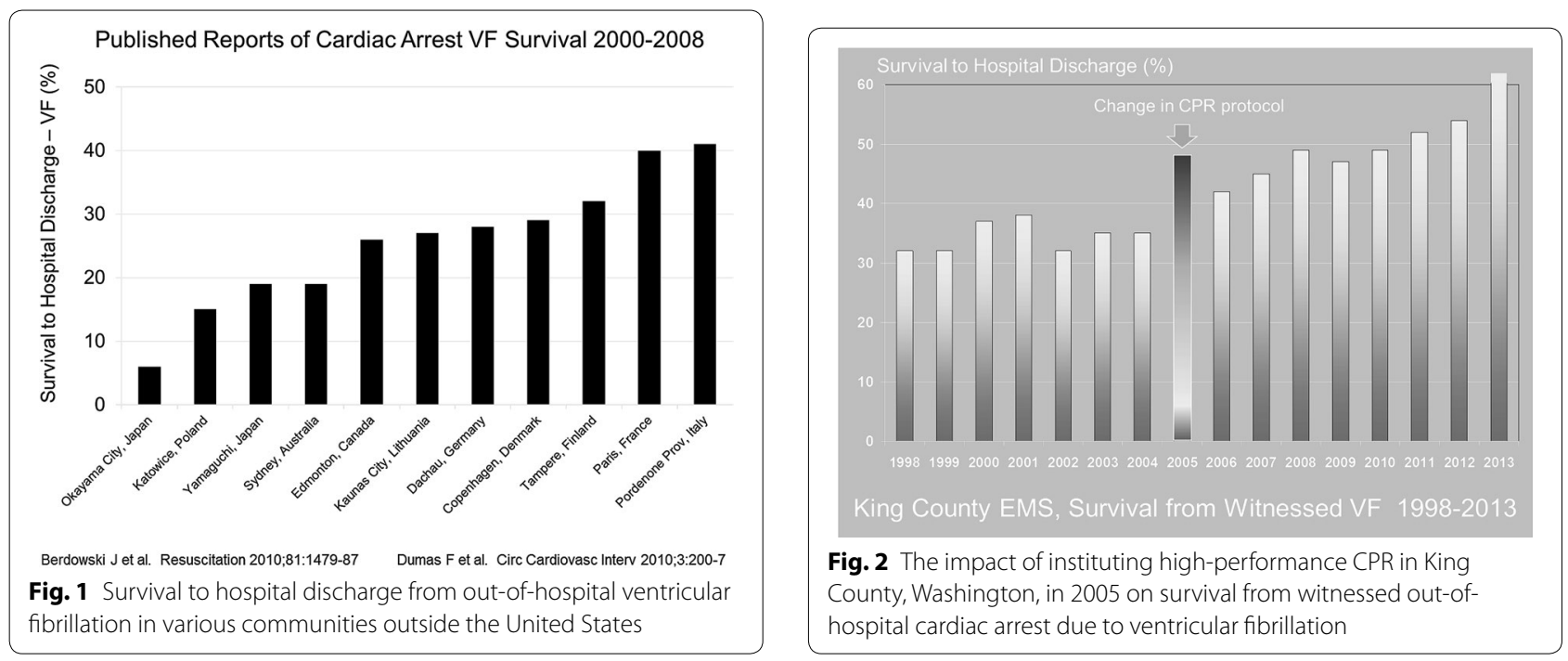
only), and has demonstrated that it can improve outcome for virtually all presentations of cardiac arrest.

While many of the identified disparities in cardiac arrest will continue to pose challenges for its management, a focus on improving systems-of-care, particularly deployment of high-performance letter-perfect CPR, offers the promise of a practical intervention that can be implemented immediately and an effort that promises to improve survival outcomes in any community.

\section{Effectiveness of rapid response systems for prevention of cardiac arrest}

Claudio Sandroni Despite the immediate availability of qualified life support, the outcome of in-hospital cardiac arrest (IHCA) remains poor. Survival to discharge after IHCA rarely exceeds $20 \%$ [9] and it has remained stable in the last 25 years (Fig. 3). Rapid response systems (RRS) have been established to prevent IHCA in non-critical care areas of the hospital [10]. Those systems are based on timely detection of deteriorating patients by the ward personnel (the afferent limb of the system), who will therefore summon a medical emergency team (MET; the efferent limb of the system), whose roles are to stabilize the patient in the ward or escalate the level of care. Although the theory underlying RRS is compelling, there is no definite evidence that their implementation improves patient outcome. The major problem in evaluating the effectiveness of RRS is the choice of the outcome measure.

The first endpoint for a study addressing the effectiveness of RRS could be the rates of unexpected cardiac arrests occurring outside intensive care units (ICUs), that is, the rates of cardiac arrest occurring in ward patients for whom there is no do-not-attempt-resuscitation (DNAR) order. This endpoint, however, is potentially biased by the fact that one of the tasks of METs is to identify ward patients for whom a resuscitation would be

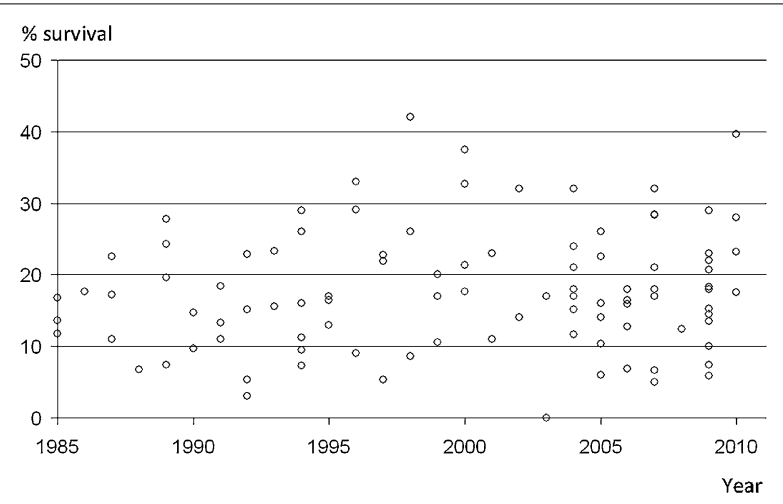

Fig. 3 The 25-year trend of rates of survival to discharge after resuscitation from in-hospital cardiac arrest in 100 observational studies, 1985-2010 inappropriate. Therefore, part of the observed reduction in the rate of unexpected cardiac arrest after the implementation of a RRS is because the fraction of expected cardiac arrests is increased by placement of a DNAR order.

Another endpoint for measuring RRS effectiveness is the reduction of unplanned ICU admissions. The rationale is that the introduction of RRS should increase the number of ICU admissions that are planned early, before further deterioration occurs, and decrease those occurring as emergency admissions after resuscitation from cardiac arrest. This model has been indirectly demonstrated for ICU admissions from Emergency Department [11] where an earlier transfer to ICU has been demonstrated to decrease both ICU and hospital mortality. However, this is not always the case with RRS. In one large American before-and-after study [12] in which almost half of the MET interventions resulted in an ICU admission, the implementation of the RRS was followed by a reduction of non-ICU codes but it did not translate in a reduction of hospital mortality. In that study, mortality in patient transferred from ward to ICU was very high, and problems of patient selection, appropriateness and timeliness of ICU transfer have been advocated to explain these results.

The third, and most comprehensive endpoint for RRS effectiveness is hospital mortality. Unfortunately, metaanalyses of available evidence on this endpoint showed conflicting results, with some studies showing benefit and others showing no or only non-significant reduction of hospital mortality after RRS implementation [13]. Moreover, the quality of evidence is relatively low, with almost all studies having a before-and-after design, which make them prone to bias due to secular trends unrelated to the study intervention or to changes in hospital case mix, a variable which is difficult to adjust for.

The ultimate strategy for assessing RSS effectiveness would be a randomized trial with concurrent cohorts, which would allow the investigators to control for most possible confounders. However, this solution is hampered by both ethical and implementation issues. Randomization at individual patient level for interventions which are commonly believed to be beneficial would in fact be ethically questionable. Cluster randomization is ethically acceptable, but difficult to implement because RRS intervention cannot be blinded, and contamination between the two study arms would be unavoidable, as did actually occur in the MERIT trial, the only randomized study conducted since now on RRS [14]. Another major implementation issue in that trial, as in general for RRS, was an afferent limb failure [15], due to an incomplete compliance of the ward personnel with the MET calling criteria. 
A final issue is reproducibility. The vast majority of studies have been made in UK or Australian-New Zealand systems, a minority of studies have been conducted in US and only very few studies have been conducted in other World areas as Continental Europe or Asia. The effectiveness of an RRS depends on the nature and the quantity of the urgent, unmet patients' needs in general wards. This model may not work in places where the severity of patients in general wards, the education of the ward personnel or the resource availability is different from that of places where this model was developed.

In summary, there are different ways of measuring the effectiveness of RRSs. The major include the rate of unexpected CA outside ICU, the rate of unplanned ICU admissions, and hospital mortality. All these outcome measures have limitations and are prone to bias. The level of evidence supporting the effectiveness of RRSs is relatively low and almost all studies have a before-and-after design. Despite the ethical and implementation difficulties, high-quality randomized trials are warranted to reliably assess the effectiveness of RRS.

\section{Pre-hospital management CPR quality has a deep impact}

Hendrik Drinhaus and Bernd Böttiger Despite enormous efforts in recent years to improve quality of cardiopulmonary resuscitation (CPR) by the development of new CPRguidelines and to enhance post-resuscitation care particularly by the introduction of mild therapeutic hypothermia and early coronary intervention, survival rates after OHCA remain unsatisfyingly low in many countries. As a prerequisite for successful post-resuscitation care on the Intensive Care Unit, high-quality CPR must be started as early as possible. As advanced life support (ALS) by emergency medical services (EMS) can only be expected to be commenced several minutes after OHCA, timely initiation of basic life support (BLS) by lay bystanders is crucial to ensure a timely perfusion of the brain and other vital organs. Sufficient perfusion can only be obtained by high-quality CPR. Hence, it is vital to increase the percentage of bystander-CPR and to improve the quality of both BLS and ALS. According to the German Resuscitation Registry, bystander-CPR is performed in less than $20 \%$ of OHCA cases [16], as opposed to $50 \%$ or more in Scandinavian countries. Large-scale programmes raising public awareness of cardiac arrest and CPR as well as providing hands-on training in BLS are a promising tool to improve survival after OHCA. In a national initiative that included CPR-training as early as in primary school, telephone guidance to CPR by EMSdispatchers, and distribution of automated external defibrillators (AED) in Denmark [17], the rate of bystander-CPR could be increased from 21 to $45 \%$ and 1-year survival raised from 3 to $10 \%$ during the intervention period. It is worth noting that the percentage of AED-use increased only from 1 to $2 \%$, which implies that the impressive improvement of outcomes of OHCA patients is rather due to prompt basic life support (as well as improved post-resuscitation care) than to AEDs. Similar initiatives are now being undertaken in Germany. Once CPR is started, its high quality is decisive for outcome. Compression depth must be sufficient (5-6 cm), frequency appropriate (100-120/min.), the chest must be released between compressions and interruptions of chest compressions must be kept as short as possible. Several studies have shown an association between these factors and survival [18-20]. During ALS by EMS-personnel, further variables are part of CPR quality: in the OHCAsetting, automated chest compression devices have failed to prove superiority to manual CPR. There is still much debate on airway management and staffing of ambulance cars. Retrospective studies have shown higher survival rates in patients who received endotracheal intubation (ETI) as compared with extraglottic airways [21, 22]. In retrospective studies, though, successful ETI might also be indicative of a generally higher skill-level of the EMS-personnel performing CPR. When using ETI during CPR, one needs to keep in mind that a high level of training is indispensable and that prolonged ETI-attempts, which go along with long interruptions of chest compressions, must be avoided. In a recent prospective, non-randomized trial, presence of a physician during CPR of OHCA-patients was associated with an impressively higher rate of survival than in patients being resuscitated by paramedics only [23], which confirms results of previous trials that observed higher survival rates in physician-staffed EMS [24]. Taken together, we can save thousands of lives each year if we manage to increase the likelihood of bystander-CPR and to optimize quality of ALS.

\section{What to perform prior to ICU admission? Percutaneous coronary intervention before hypothermia}

Hendrik Drinhaus and Bernd Böttiger Mild therapeutic hypothermia (MTH) and percutaneous coronary intervention (PCI) are both established components of post-resuscitation care after cardiac arrest, as recommended by the 2008 Statement of the International Liaison Committee on Resuscitation (ILCOR) [25]. Already then, it was suggested that indication for early PCI be extended beyond obvious myocardial infarction (STEMI), given the high probability of significant coronary artery disease in OHCA patients [26]. Since then, several trials have underlined the beneficial effects of early ( $<6 \mathrm{~h}$ after the event) PCI after OHCA also without STEMI [4, 27, 28]. Combination of PCI and MTH is feasible and does not necessarily lead to longer 
door-to-balloon times [29]. Its effects on survival and good neurological outcome appear to be synergistic [30, 31]. Hence, modern post-resuscitation care includes hypothermia and early coronary intervention (unless a non-cardiac origin of cardiac arrest is assumed or confirmed). Induction of MTH is recommended to be started as soon as possible by the ERC guidelines. Meta-analyses of the existing data on very early and prehospital induction of MTH have not shown an improvement in survival [32]. In a recent large randomized controlled trial using large volumes of icecold saline to induce MTH before arrival at the hospital, no difference in survival or neurological outcome could be found, but patients who received cold saline had a slightly higher risk of renewed cardiac arrest during transport to the hospital and of transient pulmonary oedema [33]. In the light of the findings presented hitherto, we deem it important to stress the survival benefit of early PCI after cardiac arrest not only due to definite STEMI and to raise awareness among EMS personnel to transport OHCA-patients to hospitals in which early PCI, as well as other components of post-resuscitation care, can and will be performed at any time. Prehospital cooling (at least by infusion of cold saline) on the other hand appears not to convey a benefit, maybe even a risk, and hence, not too much time and effort should be spent on aggressively lowering temperature during transport using ice-cold saline solution. In any case, induction of MTH must not delay arrival at an appropriate hospital. It appears worth considering to include into the guidelines on resuscitation and post-cardiac arrest care a recommendation to treat patients after cardiopulmonary in specialized centres that can provide early PCI, MTH and targeted temperature management as well as expert ICUtreatment wherever and whenever possible [34].
What to perform prior to ICU admission: is CT-scan useful? Alain Cariou Early identification of causes and consequences of cardiac arrest is generally considered of importance, in order to prevent recurrence and subsequent clinical deterioration. Apart from coronary angiography, a brain and chest CT-scan can also be performed at admission, when an extra-cardiac cause is suspected and in the absence of an obvious pre-hospital etiology. In a recent study, this strategy was performed in 355 patients and provided a diagnosis in 72 patients $(20 \%)$, mainly stroke and pulmonary embolism (PE) [35]. Early identification of brain damages can lead to major changes in therapy such as the use of anticoagulants. In addition, since the rate of subsequent brain death is very high in this subgroup, organ donation can be considered rapidly if an early diagnosis is achieved. Regarding PE, current guidelines underline the potential benefit of identifying this curable cause of arrest [36]. Based on prodromes and clinical evidence, an algorithm can be proposed in order to manage early imaging after cardiac arrest (Fig. 4).

\section{Thrombolysis in the treatment of cardiac arrest}

Hendrik Drinhaus and Bernd Böttiger In non-traumatic OHCA, acute myocardial infarction (AMI) and pulmonary artery embolism (PAE) account for approximately $70-80 \%$ of all cases [37]. Common feature of these aetiologies is the obstruction of vital arteries by a blood clot. Dissolving these blood clots by administering fibrinolytic substances to re-establish circulation in the respective vessel beds therefore appears to be a logical approach from a pathophysiological point of view. Several case-reports and case-series have shown impressive results in patients with presumed or documented PAE [38, 39]. Improvement of return of spontaneous circulation (ROSC) and survival

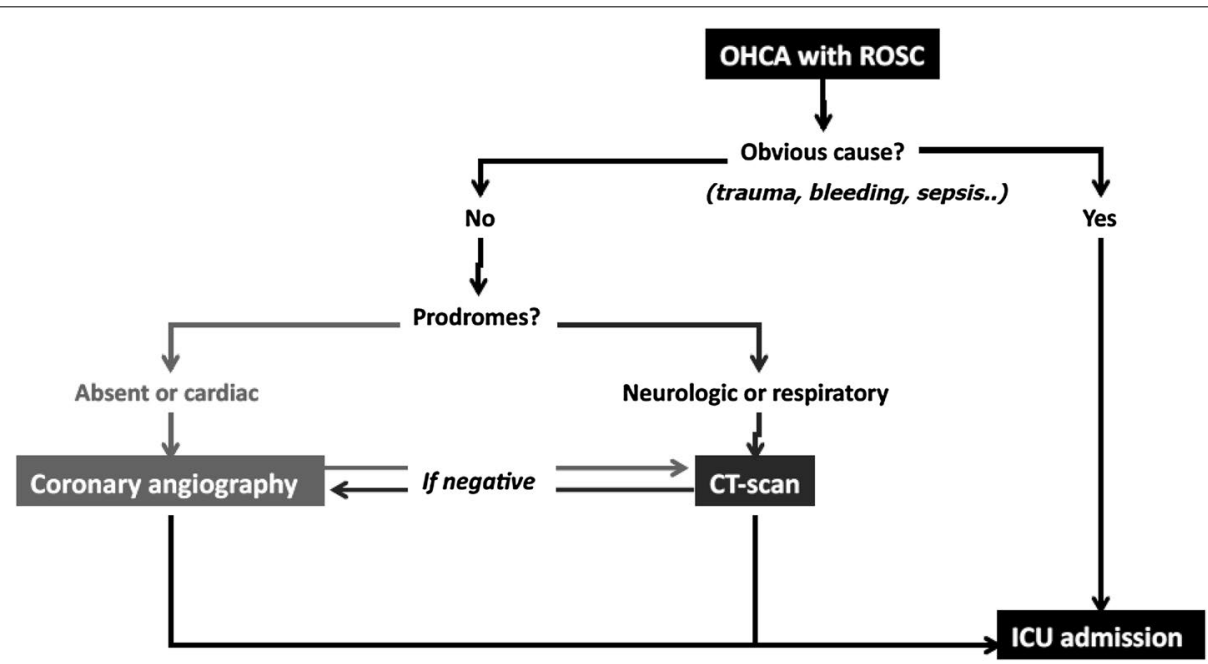

Fig. 4 Algorithm for early imaging diagnosis after cardiac arrest 
rates in patients who received thrombolysis during CPR has also been observed in non-randomised observational trials [40, 41]. A large randomised, double-blind, placebocontrolled trial- the TROICA-study-was therefore initiated to systematically evaluate thrombolysis during OHCA of presumed cardiac origin, not limited to suspected pulmonary artery embolism. In this trial, no difference with regard to ROSC or survival rates in an unselected OHCApopulation could be detected. Intracranial haemorrhage occurred more frequently in the tenecteplase-group [37]. Hence, no recommendation to administer fibrinolytics as a standard of care in all OHCA-patients could be generated from this trial. Accordingly, the current guidelines of the European Resuscitation Council recommend not to use fibrinolytics routinely during CPR. However, fibrinolytics should be considered if pulmonary embolism is the proven or suspected cause of cardiac arrest. In this case, cardiopulmonary resuscitation should be maintained for at least 60-90 min after injection of the fibrinolytic, if necessary [42]. Taken together: if a coronary cause of cardiac arrest is assumed, fibrinolytic drugs should not be used and prompt coronary revascularisation, usually by percutaneous coronary intervention, is the treatment of choice-even during ongoing CPR. Fibrinolytics must be considered if pulmonary artery embolism is the suspected or proven cause of cardiac arrest.

\section{CPR is better without epinephrine in cardiac arrest!}

Kjetil Sunde Whereas there is clear evidence for improved survival with CPR and defibrillation during cardiac arrest management, there is today lacking evidence that any of the recommended and used drugs leads to any long-term benefit for the patients. Thus, until we have better drugs or combination of drugs, ALS can be performed without the use of drugs, and instead gains all focus on improving the tasks we know improve survival. Good-quality CPR, early defibrillation together with goal-directed post-resuscitation care is way more important than giving drugs with no proven benefit [43]. More drug studies are indeed required, and future research needs to incorporate better diagnostic tools to test more specific and tailored therapies that account for underlying aetiologies and individual responsiveness. We should expand our diagnostic capabilities exploring the feasibility of utilizing technologies such as capnography, near-infrared spectrophotometry (NIRS), VF analysis, and ultrasound assessment to allow targeted therapy (while maintaining adequate CPR). When good quality of care and improved diagnostics have been ensured, more tailored drug approaches could eventually be tested based on underlying etiologies.

\section{ECMO for cardiac arrest: ECMO is futile}

Martin Dworschak Extended time periods of no and low flow after CA are generally associated with poor outcome. Although return of spontaneous circulation can be achieved after more than 20 min of CPR, only few patients will survive with good functional outcome [44, 45]. By rapid deployment of ECMO in patients with refractory conventional CPR (CCPR) systemic blood flow can be maintained to prevent irreversible organ damage. The best results with extracorporeal CPR (ECPR) have been obtained so far in neonates and children when ECPR was instituted during in-hospital cardiac arrests that had short response times. The benefit of ECPR in adults being resuscitated for in- or OHCA is less clear. One major confounder is the fact that ECPR is frequently considered for a highly selected patient population (young age, ventricular fibrillation as the initial cardiac rhythm, witnessed arrests with immediate bystander CPR) only [46]. Nevertheless, quoted survival rates after ECPR [47] are either comparable with those in CCPR patients [48] or slightly better, but this does not seem to impact on neurological outcome [46, 49]. Accordingly, in 2010 the American Heart Association did not recommend the routine use of ECPR [50]. Yet, it could be taken into consideration when it is readily available and the no-flow duration is brief. Furthermore, the conditions that led to the arrest should either be reversible or amenable. Particularly in OHCA, however, most patients are neither young nor hypothermic or intoxicated and they do not present with a shockable rhythm; fewer CAs are witnessed and the quality of BLS/ALS is usually unknown. Another handicap in OHCA appears to be fast deployment of ECMO with quick institution of therapeutic hypothermia [51]. Although ECPR seems to improve survival, especially after long-duration CPR, the rate of neurologically intact survivors still remains low. Future research should define criteria for the optimal indication of ECPR and criteria for ECPR as a bridge to LVAD, HTX, or organ procurement to guarantee efficient use of precious and scarce resources. Randomized controlled trials, as well as crucial analysis of uniformly reported CA data from registries would greatly facilitate decision-making.

\section{Post-resuscitation management: targeted temperature management \\ How to cool?}

Fabio Taccone Several cooling methods, both invasive and non-invasive, are currently used to achieve target temperature after post-anoxic brain injury. Invasive methods include the administration of intravenous cold fluids or the use of endovascular cooling catheters [52]. The use of 
cold $\left(4^{\circ} \mathrm{C}\right)$ fluid infusion is cheap and easy-to-use, even in the pre-hospital setting. This method is generally recommended to initiate cooling in comatose survivors after $\mathrm{CA}$, either alone or in conjunction with other cooling systems [53]. A 2-1 bolus given over 30-60 min immediately after ROSC was associated with a mean decrease in core temperature of $1.3{ }^{\circ} \mathrm{C}$ [54]. This method is largely used also to induce hypothermia in the fields [33]. However, cold fluids are not effective to maintain target temperature [55] and, because of potential excessive volume-loading and reduced coronary perfusion pressure [56], have been recently associated with an increased risk of re-arrest and pulmonary oedema when given before hospital admission [33]. The endovascular cooling catheter contains a circulating cold solution, which is maintained at a controlled temperature; this method can easily achieve a cooling rate of $1.5-4.5^{\circ} \mathrm{C} / \mathrm{h}$ [52]. Moreover, the use of an endovascular system reduced the variability of body temperature around the target value and increased the proportion of time that patients spent within the therapeutic temperature targets during the maintenance phase [57]. Main limitations are related to the time to insertion into a large vein, the need of a bedside heat exchanger with energy supply (i.e. limited used outside the ICU) and the potential risk of venous thrombosis or infection [58].

Non-invasive methods include external surface and ice packs or pads. Modern cooling blankets or fluid pads usually operate with a continuous temperature feedback mechanism, which reduced the risk of temperature variability and overcooling, and present a cooling rate around $1.2-2.5{ }^{\circ} \mathrm{C} / \mathrm{h}$ in $\mathrm{CA}$ patients $[52,59]$. Unfortunately, these devices also depend on an external energy supply and it remains difficult to use them outside the ICU. Ice packs can be easily applied to different areas of the body, are inexpensive and are not dependent on an external energy source; however, the cooling rate is extremely poor $\left(<1^{\circ} \mathrm{C} / \mathrm{h}\right)$ and could expose patients to overcooling, as there is no feedback temperature control. Ice pads can provide a faster cooling rate (up to $3{ }^{\circ} \mathrm{C} / \mathrm{h}$ ) after $\mathrm{CA}$, but they have been associated with thermal skin damage on the sites of application [60].

An attractive alternative to these methods is to induce brain hypothermia, especially because of the decreased risk of side effects associated with whole-body cooling. Cranial cooling cap devices placed around the head and neck can easily decrease tympanic temperature; however, they are mostly effective in children because of their favourable ratio of head-to-body surface area [61]. Nasopharyngeal cooling devices, which use volatile coolant fluids via a specific nasal catheter, can rapidly reduce brain temperature with a concomitant reduction of core temperature around $1.0-1.5{ }^{\circ} \mathrm{C} / \mathrm{h}$ [62]. These systems are quite safe, are not dependent on an external energy source and can be initiated even during cardiopulmonary resuscitation [63]. Alternatives methods for cooling could be continuous renal replacement therapy, peritoneal lavage and, in case of severe cardiogenic shock, the use of extracorporeal membrane oxygenation (ECMO) devices; however, these methods are particularly invasive and their use has been limited to very selected cases [64-66].

Finally, no prospective study has shown a clinical superiority of one method to another, while some retrospective reports suggest a better survival rate for endovascular cooling when compared to surface cooling methods $[67,68]$. Importantly, the endovascular catheter and modern surface devices have significant higher costs than intravenous fluids and ice packs [69]; however, their use was associated with an important reduction of nurse workload and improvement in patients' care [70].

\section{For how long?}

Kjetil Sunde The precise description of patients that will benefit from therapeutic hypothermia (TH), or targeted temperature management (TTM), the ideal induction technique (alone or in combination), target temperature, optimal maintenance and rewarming times have yet to be established. Independently of the cooling method chosen, $\mathrm{TH}$ is easy to perform, and without severe side effects or complications associated with mortality. As for the duration of TH/TTM, the majority of centers use $24 \mathrm{~h}$ as their treatment strategy; however, we are lacking of clinical data comparing different durations. Newborn asphyxial arrests are treated with $\mathrm{TH}$ for $72 \mathrm{~h}$, with several RCTs proving its benefit compared to normothermia/fever. In a recent animal study, post-cardiac-arrest TH resulted in comparable improvement of survival and survival with good neurologic function when initiated within $4 \mathrm{~h}$ after return of spontaneous circulation. Interestingly, histological assessment of neuronal survival revealed a potentially broader therapeutic window and greater neuroprotection when TH was maintained for 48 versus $24 \mathrm{~h}$ [71]. However, this benefit was not seen in the neurological outcome evaluation. In a clinical registry study among approximately 1000 cooled comatose cardiac arrest patients, factors related to the timing of TH had no apparent association to outcome (Fig. 5).

\section{Any evidence for non-shockable rhythm patients?}

Nicolas Deye According to international guidelines, therapeutic hypothermia (TH) might also benefit comatose adult $\mathrm{CA}$ patients with spontaneous circulation after resuscitation from a non-shockable rhythm [72]. However, there is no large randomized controlled trial evaluating the clinical impact of $\mathrm{TH}$ in this situation. Using $\mathrm{TH}$ for nonshockable CA patients is supported by only low level of 


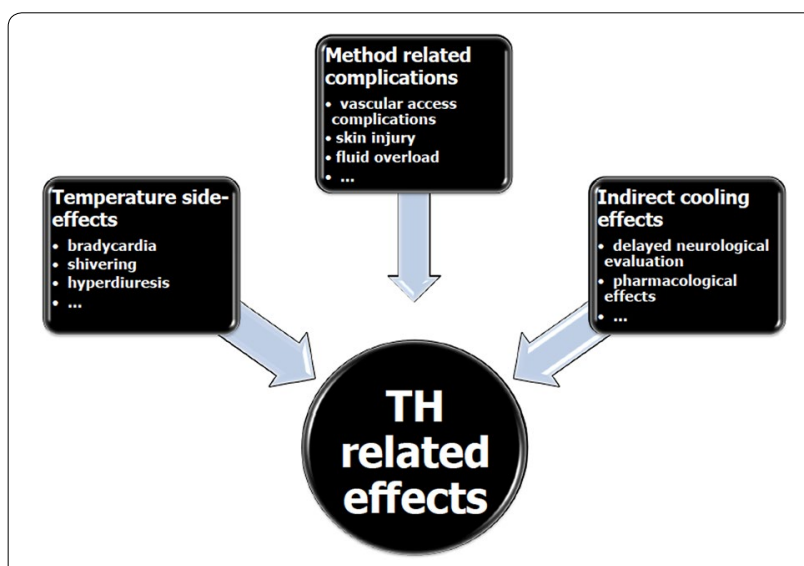

Fig. 5 Therapeutic hypothermia side-effects and their categorization

scientific evidence and extrapolation of data resulting from shockable rhythms. Consequently, the potential impact of TTM including TH-implementation remains controversial for CA patients presenting with initial non-shockable rhythm [73, 74]. Treating such patients becomes a major health issue, as the proportion of these patients increases over decades while the proportion of OHCA patients resuscitated from shockable rhythms declines and now represents the minority of OHCA patients [75]. Prognosis of patients experiencing CA still remains poor. However, large registries reported recently for non-shockable CA patients hospitalized in ICU survival up to $26 \%$, favourable neurological outcome at 6 months of $22 \%$, and survival rate at 10 years after hospital discharge alive reaching $43 \%[76,77]$.

The pro-con debate on the use of $\mathrm{TH}$ in non-shockable patients has been previously described [74]. Briefly, some argue in favour of the use of $\mathrm{TH}$ in non-shockable CA patients: (1) the pathophysiological processes responsible of post-anoxic (brain) damages seem independent of the initial rhythm (i.e. shockable versus non-shockable); (2) most of experimental and animals studies strongly support the use of TH in asphyxia and CA models irrespective of the initial rhythm; (3) with more than 10 concordant large randomized controlled trials and metaanalyses, TH initiated within $6 \mathrm{~h}$ and targeted to 32.5$35.5{ }^{\circ} \mathrm{C}$ for $72 \mathrm{~h}$ is unequivocally beneficial on survival and neurological outcome in newborns who sustained asphyxia (with or without cardiopulmonary resuscitation: CPR) and exhibit acidosis and/or neonatal hypoxicischaemic encephalopathy [73, 74, 78]; (4) TTM with $\mathrm{TH}$ is potentially the unique available treatment to date prone to minimize brain damages and long-term disabilities, and to increase survival without major sequelae in non-shockable CA patients [74]; (5) some observational, retrospective or prospective, but non-randomized clinical studies observed a benefit of TH in non-shockable CA adults patients, with one meta-analysis suggesting a reduced in-hospital mortality without improvement of the neurological outcome in these patients.

Conversely, the potential increased TH-related side effects are not in favour of the use of $\mathrm{TH}$ in non-shockable CA patients. Adverse events include the increased delay in time to recovery of consciousness leading to a prolonged delay to evaluate the neurological recovery. This delay seems mainly induced by the use of sedatives and neuromuscular blockers often required during the $\mathrm{TH}$ use, leading to a possible prolongation of mechanical ventilation and hospitalization durations, and consequently of ICU costs. The increased incidence of other main side effects, essentially pneumonia and sepsis, could be another explanation altering the risk/benefit ratio of $\mathrm{TH}$, although neither firmly established nor related to the initial CA rhythm [74, 76, 79].

Additionally, several studies describing non-shockable CA patients have not shown significant prognostic effect of TH [74]. Most of the studies included in the first metaanalysis evaluating this issue presented substantial risks of bias and a very low quality of evidence. Thus the beneficial effect observed for in-hospital mortality was no longer significant when analysis was restricted to the two small RCTs available. Another meta-analysis similarly concluded that the group sizes for patients with asystole or non-cardiac causes of CA were too small to draw conclusions. At least, several recent non-randomized controlled studies-after adjustment in some studiesreported negative or even harmful $\mathrm{TH}$-effects on outcome in this population [74, 80-82]. Similarly, with a TH implementation in nearly $50 \%$ of patients and a global hospital survival of $2 \%$ in the non-shockable rhythm group, TH was not significantly associated with hospital survival after adjusting for other prognostic factors [75].

Beyond ethical considerations regarding the $\mathrm{TH}$ related futility/benefit ratio, some major issues remain unsolved regarding the ideal TTM in this specific population.

The correct selection of patients that could benefit or not from TTM or TH-implementations seems critical in this heterogeneous group, as well as the underlying comorbidities and severity of the post-resuscitation syndrome [74]. Indeed an initial non-shockable rhythm may represent: (1) either the first documented CA rhythm resulting from a severe non-cardiac aetiology with its own prognosis per se; (2) or the consequence of an initial shockable CA with a prolonged time to first CPR leading to prolonged ischaemic times, severe brain damages and/ or multiple organ failures. A non-prolonged time from collapse to return of spontaneous circulation (i.e. sum of the time to first CPR plus the duration of CPR) could be 
a relevant prognosis factor able to identify patients who may mostly benefit from cooling independently of the initial rhythm. Conversely in witnessed-OHCA patients, the more prolonged is the time from collapse to first CPR the better could be the TH-benefit after adjustment on other factors including the initial rhythm. The target population in non-shockable patient probably results from a complex balance between patients that can benefit from $\mathrm{TH}$ (i.e., those with $\mathrm{TH}$-accessible brain damages with adequate durations of time to first CPR and CPR durations) versus those who do not (i.e., those with multiple organ failure or too severe prognosis that could lead to early death or early treatments withdrawal). Additionally, the TH-implementation in non-shockable patients is often left at the bedside physician's discretion in most studies evaluating this issue, and important bias should be introduced regarding the correct selection of patients $[74,83]$.

At last, the aetiology and/or mechanisms responsible for fever are possibly a key issue to correctly evaluate patients able to receive a TTM or a TH implementation, especially after CA occurrence in non-shockable patients. In a large population of unselected ICU patients, fever was not always associated with a poor prognosis and control of fever was not always associated with better prognosis, with important differences existing between septic and non-septic patients [84]. PostCA syndrome often mimics a sepsis-like syndrome. The correct discrimination of patients who may benefit for a strict normothermic control, those who may benefit for a TH implementation targeted to $32-35^{\circ} \mathrm{C}$, versus those who may-or not-benefit for a fever control within the 48-72 $\mathrm{h}$ after CA to avoid rebound hyperpyrexia, is the next step to optimize the temperature control after CA in the non-shockable population $[74,85]$.

The choice of the correct target temperature as the precise achievement of goal temperature seems also crucial in these patients. The recommended treatment for all post-CA patients is at present an early $\mathrm{TH}$-implementation of $12-24 \mathrm{~h}$ targeted to $32-34{ }^{\circ} \mathrm{C}$ [72]. An adapted scheme of TTM could be of critical importance in non-shockable patients, regarding the optimal duration, speed cooling, level of temperature, therapeutic window, and rewarming rate of TTM, considering that the cerebral damages may be more severe in this population [72, 74]. Interestingly, in the large recent TTM-trial including $20 \%$ of patients presenting with an initial nonshockable rhythm out of a total 939 enrolled patients, no difference were found between the 2 studied arm, i.e. 33 versus $36{ }^{\circ} \mathrm{C}$ applied for $28 \mathrm{~h}$. The TTM-scheme included in both groups a gradual rewarming $<0.5^{\circ} \mathrm{C} / \mathrm{h}$ to reach $37{ }^{\circ} \mathrm{C}$, with tapering or discontinuation of the mandatory sedation at $36 \mathrm{~h}$, and a maintenance of body temperature for unconscious patients $<37.5^{\circ} \mathrm{C}$ until $72 \mathrm{~h}$ after CA [86]. Similar results were herein observed in all pre-planned subgroups including analyses performed according to initial rhythm (i.e. non-shockable versus shockable), suggesting that "strict normothermia" targeted to $36^{\circ} \mathrm{C}$ should be an alternative in non-shockable rhythm CA patients.

This ongoing debate clearly underlines the need for a large multicentre study evaluating the effects of different scheme of TTM and TH in non-shockable CA patients after careful patients' selection, including insights in subgroups according to the pathophysiology of the CA. To date, the indication for $\mathrm{TH}$ in non-shockable patients should be based using a case-by-case approach, whereas a TTM approach targeting strict normothermia remains reasonable for these patients.

\section{Hypothermia-associated complications}

Alain Cariou Besides infections, several other adverse events such as arrhythmias, seizures, bleeding or thrombosis, electrolyte and metabolic disorders, occur commonly in comatose patients treated in critical care units after outof-hospital cardiac arrest. These events may be related to the cause precipitating the cardiac arrest, the post-cardiac arrest syndrome or the critical care treatment. As it may affect many physiologic processes and responses, hypothermia itself is commonly suspected to promote these events (Fig. 2) [87]. However, most of these events are probably not related to $\mathrm{TH}$, as suggested by the results of a recent Cochrane systematic review that revealed no significant difference in reported adverse events between hypothermic and control patients [88]. Regarding metabolic disorders, rapid changes in glycemia are possibly the most clinically relevant event that could be worsened by hypothermia $[89,90]$. As it may worsen brain damages, it suggests minimizing glycaemic variations during the postresuscitation period. In addition, TH most often requires sedation, ventilation, and neuromuscular blockade, which may delay the possibility of neurological evaluation.

\section{What is a real targeted temperature management: TTM at $36{ }^{\circ} \mathrm{C}$}

Hans Friberg In 2002, two landmark trials were published showing that lowering body temperature to $33{ }^{\circ} \mathrm{C}$ improved neurological outcome and saved lives in comatose survivors of out-of-hospital cardiac arrest [52, 91]. This therapy was rapidly adopted by international guidelines and not questioned until a systematic review using the GRADE methodology and trial sequential analysis showed that the quality of the evidence for treating cardiac arrest patients at $33{ }^{\circ} \mathrm{C}$ was low [86]. Criticism included the low number of enrolled patients and the fact that both trials had 
weaknesses, including quasi-randomization, lack of power analysis and early stopping which was not adjusted for. Furthermore, patients in the control groups were treated according to standard care of that time which allowed fever [92].

This led to the design of a new trial, randomizing patients to two controlled temperatures, 33 and $36{ }^{\circ} \mathrm{C}$ [93]. The Target Temperature Management after Outof-hospital Cardiac Arrest trial (TTM-trial) included and randomized 950 patients in 27 months, almost three times the number of the two previous trials combined. Thirty-two sites enrolled patients in nine countries in Europe plus Australia. The TTM-trial differs from previous trials in several aspects, the most important one being that all patients received controlled temperature management avoiding fever in both intervention arms (Fig. 6). Other differences include a contemporary setting with improved pre-hospital care with a high bystander CPR rate, and improved hospital care in patients with ROSC. For example, two of three patients in the TTMtrial received an early angiography $(<24 \mathrm{~h})$. Other quality criteria that were acknowledged in the TTM-trial, as opposed to previous trials, were that the design and the statistical analysis plan were published in advance. [93, 94] In addition, prognostication of comatose patients was performed according to a strict and predefined protocol and the rules for decisions on withdrawal of life-sustaining therapy (WLST) were transparent and published in advance [90]. The primary outcome was survival until the end of trial. A neurological assessment, using both the Cerebral Performance Category scale (CPC) and the modified Rankin Scale (mRS), was performed at 6 months and was blinded.

In summary, the TTM-trial has sent a clear message to the medical community that no difference in survival (Fig. 7) or neurological outcome could be detected when

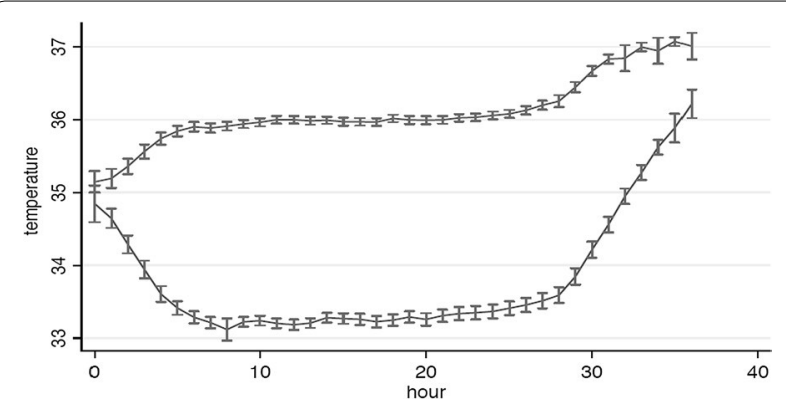

Fig. 6 Mean bladder temperature in the 33 and $36{ }^{\circ} \mathrm{C}$ intervention groups of the Target Temperature Management after Out-of-hospital Cardiac Arrest Trial (TTM-trial), during the $36 \mathrm{~h}$ of temperature intervention. Temperature values are presented with $95 \%$ confidence intervals. In the original publication, temperature curves displayed the means $\pm 2 S D$. From Wise MP et al. [179]. Reprinted with permission

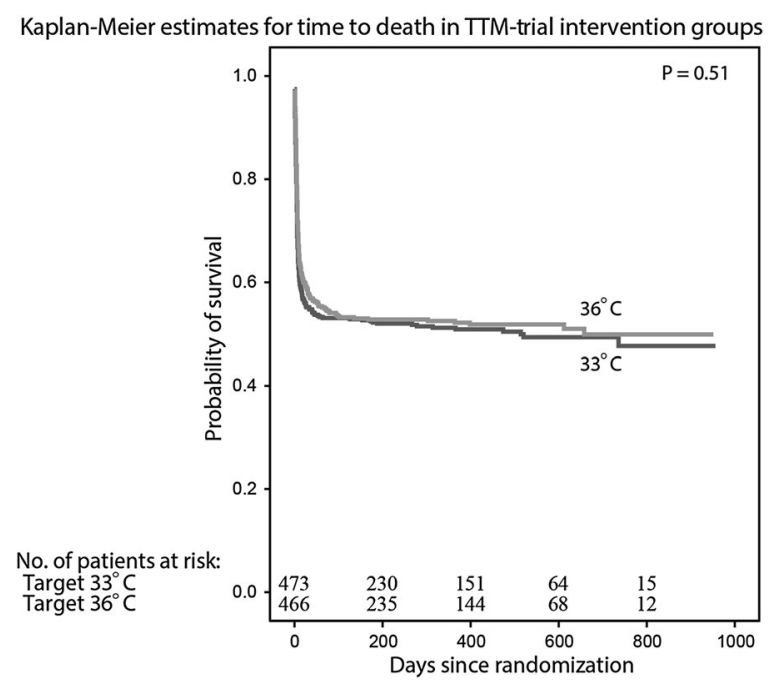

Fig. 7 The TTM-trial included and randomized 950 comatose patients to either 33 or $36^{\circ} \mathrm{C}$. Probability of survival through the end of the trial and the number of patients at risk at each time point is presented. From Nielsen et al. [86]. Copyright (c) (2013) Massachusetts Medical Society. Reprinted with permission

comatose patients after cardiac arrest were treated at either 33 or $36^{\circ} \mathrm{C}$ [86]. We can therefore conclude that a real target temperature management after cardiac arrest is a controlled temperature at either of the two temperatures, both avoiding fever. This should be part of a bundle of care, including treatment of acute coronary disease and contemporary and active intensive care.

Our rationale for changing to $36{ }^{\circ} \mathrm{C}$ is that this temperature is closer to normal and less invasive, reducing known and unknown risks. The number and severity of adverse events in the two intervention arms did not differ in the TTM-trial, although there was a tendency towards less events in the $36^{\circ}$-arm $(p=0.086)$. Treating the patients closer to normal temperatures allows for predictable drug effects, including those of sedatives and antithrombotic therapy. In a recently published post hoc analysis of the TTM-trial of the subgroup of patients in circulatory shock at admission, a higher mortality at ICU discharge was suggested in the $33^{\circ} \mathrm{C}$-arm (66 versus $44 \%$, adjusted $p$ value 0.03 ) [95]. We cannot exclude that other subgroups may benefit from treatment at $36^{\circ} \mathrm{C}$ or for that matter, from treatment at $33^{\circ} \mathrm{C}$. The optimal temperature, duration of temperature management and target population are yet to be defined.

\section{Post-resuscitation management: optimizing organ} perfusion and metabolic parameters Oxygen and carbon dioxide after cardiac arrest: friend or foe? Nicolas Deye In CA patients, neurological injury is a major cause of mortality [72]. A first hypoxo-anoxia phe- 
nomenon occurs initially during CA before and during CPR maneuvers. The ischemia-reperfusion syndrome occurring in the post-resuscitation phase after obtaining an ROSC can lead to secondary insults including oxidative stress with free radical formation or mitochondrial dysfunction $[72,96]$. Oxygen $\left(\mathrm{O}_{2}\right)$ and carbon dioxide $\left(\mathrm{CO}_{2}\right)$ abnormalities can promote these insults. Targeted temperature management (TTM), including therapeutic hypothermia (TH) targeted to $32-34{ }^{\circ} \mathrm{C}$, is one of the therapeutic measure improving prognosis and neurological outcome after CA. Induced hypothermia could minimize the CArelated injuries by decreasing $\mathrm{O}_{2}$ free-radical production, mitochondrial dysfunction, brain $\mathrm{O}_{2}$ consumption [96]. Thus TH could minimize neuronal death and improve neurological outcome and survival. However, hypothermia is associated with several arterial blood gas (ABG) modifications, mainly induced by the leftward shift of the hemoglobin dissociation curve, increased $\mathrm{O}_{2}$ and $\mathrm{CO}_{2}$ solubility, modification of the $\mathrm{pH}$ regulation, with hypoventilation and hypometabolism, leading per se to hypoxia and hypocapnia. Iatrogenic dyscarbia incidence (hypo- or hyper-carbia) has been reported up to $69 \%$ [97], hypoxia up to $63 \%$ [98], and hyperoxia up to $41 \%$ [99]. International guidelines mainly focused on potential hypocapnia and hypoxia/ hyperoxia harmful effects for CA patients [72, 100]. They advocate initial resuscitation with $100 \% \mathrm{O}_{2}$ ventilation to avoid hypoxia followed by a titration of $\mathrm{O}_{2}$ therapy targeting arterial $\mathrm{O}_{2}$ saturation levels between 94 and 96(-98)\% especially during the initial post-CA period to avoid hyperoxia.

Beyond general detrimental effects such as decreased stroke volume, cardiac output and coronary blood flow and increased systemic vascular resistances, potential neurological harm of $\mathrm{O}_{2}$ therapy have been largely described [100, 101]. Hyperoxia can exacerbate cellular oxidative stress injury and mitochondrial dysfunction to key mitochondrial enzymes or mitochondrial lipids, leads to cerebral $\mathrm{O}_{2}$-related vasoconstriction with a decreased cerebral blood flow (CBF) and cerebral energy metabolism impairment. It can increase the neuronal lipid peroxidation and protein oxidation, enhance $\mathrm{O}_{2}$ free radical formation and reactive $\mathrm{O}_{2}$ species, or react with nitrite oxide to produce toxic metabolites (peroxynitrite, superoxide ion, hydrogen peroxide). All of this will finally participate to cell death. Despite several limitations or controversial results in specific experimental models [100-102], most animal studies have suggested that hyperoxia after CA could worsen neurological outcome [103].

In a retrospective cohort including 145 adult OHCA patients with available arterial $\mathrm{O}_{2}$ pressure $\left(\mathrm{PaO}_{2}\right)$ on ABG sample during CPR attempts, an increased $\mathrm{PaO}_{2}$ was associated with improved rate of hospital admission alive in multivariate analysis [104]. Incidence of hyperoxia defined as $\mathrm{PaO}_{2}>300 \mathrm{mmHg}$ reached $14 \%$, whereas hypoxia was defined as $\mathrm{PaO}_{2}<60 \mathrm{mmHg}$. The potential deleterious effect of hypoxia during the resuscitative efforts has been also found in another recent retrospective study [100].

Most clinical studies depicting the $\mathrm{O}_{2}$ effects after ROSC from CA are methodologically of low level quality. The only small randomized clinical trial evaluating this issue found a significant decreased value of the Neuron Specific Enolase biomarker in favor of a normal level of $\mathrm{PaO}_{2}$ versus a high level $\mathrm{PaO}_{2}$ in the subgroup of patients without TH [105]. However, this result was not observed for the S100B Protein biomarker and in the whole cohort including the 28 patients regardless $\mathrm{TH}$ implementation. Hypoxia and hyperoxia harmful effects regarding in-hospital mortality and functional status were initially described in a large American registry in 2010 [98]. Several issues have been pointed out for these studies: (1) the statistical methods (registries and databases versus scarce randomized studies, retrospective versus prospective studies, single center versus multicentre studies, adjustment not usually performed to control for other potential confounders); (2) the definitions regarding hyperoxia thresholds (i.e. what precise level of $\mathrm{PaO}_{2}$ to choose?); (3) the different time-point measurements and the period of data collection (i.e. what value to consider between the first $A B G$, the $A B G$ on admission, the $A B G$ within the first hours or the first day after ROSC or CA, between the mean or median versus the maximal or minimal $\mathrm{PaO}_{2}$ values or the worst $\mathrm{PaO}_{2}$ using worst $(\mathrm{A}-\mathrm{a}) \mathrm{DO}_{2}$ or the $\mathrm{PaO}_{2} / \mathrm{FiO}_{2}$ ratio?); (4) the associated treatments (i.e. $\mathrm{TH}$ versus the absence of TTM); (6) the best endpoint (i.e. inhospital mortality versus neurological outcome).

A recent meta-analysis concluded that hyperoxia in the post-resuscitation phase after ROSC was significantly associated with an increased in-hospital mortality [99]. Conversely, the poor neurologic outcome at hospital discharge did not reach significance suggesting a possible lack of association or a review underpowered. However, these results need further confirmation because of its significant heterogeneity (results were inconsistent in subgroup and sensitivity analyses) and the limited number of studies analyzed ( 3 abstracts out of the 10 pooled studies were finally included). Since this review, two other studies describing a low hyperoxia incidence rate (3 and $6 \%$ ) have been published $[106,107]$. The potential harmful effect of hyperoxia regarding mortality was not significant. In only one of these 2 studies [106], hyperoxia was significantly associated with poor neurological outcome in the multivariate analysis, depicting a "V-shaped" relationship between probability of unfavorable outcome and the mean $\mathrm{PaO}_{2}$ value obtained from ROSC to rewarming. 
Cerebral autoregulation physiologically maintain a constant CBF within a large range of mean arterial pressure $[100,108]$. This relationship is modified by dyscarbia as cerebral perfusion depends on $\mathrm{CO}_{2}$. Hypercapnia leads to cerebral vasodilation and potentially increased intracranial pressure, whereas hypocapnia leads to cerebral vasoconstriction and potentially ischemia (decreasing $\mathrm{PaCO}_{2}$ of $1 \mathrm{mmHg}$ can decrease $\mathrm{CBF}$ up to $3 \%$ ). Ensuring physiological $\mathrm{CO}_{2}$ tension in $\mathrm{CA}$ patients seems important to prevent worsening of the neurological status. Furthermore, impaired autoregulation has been described in some brain-injured areas, in some TH-treated patients, and inconstantly in CA patients. Recommendations in resuscitated CA patients suggest a $\mathrm{PaCO}_{2}$ target of $40-45 \mathrm{mmHg}$ during the post-ROSC period in this population of brain-injured patients regardless of $\mathrm{TH}$ use [72, 100]. In a retrospective single-center study implementing $\mathrm{TH}$ in $41 \%$, hypocapnia (defined by $\mathrm{PaCO}_{2} \leq 30 \mathrm{mmHg}$ ), hypercapnia $\left(\mathrm{PaCO}_{2} \geq 50 \mathrm{mmHg}\right)$, and association of both dyscarbia occurring within the first $24 \mathrm{~h}$ after ROSC were all independently associated with poor neurologic outcome at hospital discharge [97]. An observational multicenter registry recently enrolled 16.542 adult CA patients $\mathrm{TH}$-treated in $39 \%$. Increased in-hospital mortality and rate of poor outcome were observed in the hypocapnia group compared to normocapnia after adjustment for illness severity and propensity score [109]. Conversely, hypercapnia $\left(\mathrm{PaCO}_{2} \geq 45 \mathrm{mmHg}\right)$ within the first $24 \mathrm{~h}$ after admission was independently associated with similar in-hospital mortality and a higher rate of discharge home among survivors. In a smaller study of $\mathrm{TH}-$ treated patients, hypocapnia but not hypercapnia was independently associated with an increased risk of inhospital death [106]. A "U-shaped" relationship between the mean $\mathrm{PaCO}_{2}$ and the in-hospital mortality was found with the best survival observed for the normocapnia group (35-45 $\mathrm{mmHg}$ ). No association between hypoand hyper-capnia with poor neurologic outcome were observed. Another recent multicenter and prospective study applying $\mathrm{TH}$ in $71 \%$ defined $\mathrm{PaCO}_{2}$ as "low" when $<30 \mathrm{mmHg}$, "middle" when $30-37.5 \mathrm{mmHg}$, "intermediate" when 37.5-45 $\mathrm{mmHg}$, and "high" when $>45 \mathrm{mmHg}$ [107]. Patients with poor versus good outcome had similar highest, mean and lowest $\mathrm{PaCO}_{2}$. The mean 24-h $\mathrm{PaCO}_{2}$ and the time spent in $\mathrm{PaCO}_{2}>45 \mathrm{mmHg}$ regardless $\mathrm{TH}$-implementation were independently associated with better 1-year good outcome. However, same criticisms can be made for all these studies than those made above regarding statistics, threshold, data collection, or treatments. To date mainly because of paucity of data on this issue, no clear thresholds have been found regarding the harmful impact of hypo- or hyper-capnia after CA. Whereas hypocapnia seems consistently associated with worse outcome, hypercapnia is not [100]. The management of $\mathrm{PaCO}_{2}$ after CA by using specific mechanical ventilation strategy could influence the outcome of these patients especially during $\mathrm{TH}$. In a recent retrospective study focusing on initial post-CPR mechanical ventilation settings minute ventilation was weakly correlated with the initial $\mathrm{PaCO}_{2}$ [110]. Normocapnia alone (31$49 \mathrm{mmHg}$ ) was again associated with a better favorable neurological outcome.

ABG measurements performed at $37{ }^{\circ} \mathrm{C}$ are secondarily expressed either as temperature-corrected or uncorrected according to biochemical centers [108]. Substantial discrepancies can be related to these methods: $\mathrm{PaO}_{2}=100 \mathrm{mmHg}$ at $37{ }^{\circ} \mathrm{C}$ becomes $79 \mathrm{mmHg}$ if corrected at $33{ }^{\circ} \mathrm{C}$, when $\mathrm{PaCO}_{2}=36 \mathrm{mmHg}$ becomes $30 \mathrm{mmHg}$ at $33^{\circ} \mathrm{C}$. There are no clear recommendations regarding the ventilation strategy to be used in resuscitated CA patients despite such differences. Normocapnia in hypothermic patients can be achieved according to two different mechanical ventilation strategies: $\alpha$-stat versus $\mathrm{pH}$-stat. In the $\alpha$-stat strategy ventilation is set to achieve physiological arterial $\mathrm{CO}_{2}$ tension measured at $37^{\circ}$, unadjusted to the patient's temperature, whereas in the $\mathrm{pH}$-stat strategy ventilation is set to achieve physiological arterial $\mathrm{CO}_{2}$ tension measured at the patient's actual temperature. The latter strategy leads to a relative hypoventilation compared to the $\alpha$-stat strategy. Using either $\alpha$-stat or $\mathrm{pH}$-stat strategy to guide normocapnia after CA remain open to discussion. In the recent multicenter Finnish study focusing on ABG abnormalities after CA, 13 ICUs used temperature-correction; whereas, eight did not [107]. Two recent exploratory studies in TH-treated CA patients compared either a "lower versus upper threshold normocapnia" (32 versus $45 \mathrm{mmHg}$ ) or the $\alpha$-stat versus the $\mathrm{pH}$-stat strategies while maintaining a $\mathrm{PaCO}_{2}$ target level between 36 and $42 \mathrm{mmHg}$. The first study showed that the "lower threshold normocapnia" induced decreased internal jugular vein $\mathrm{O}_{2}$ saturation and $\mathrm{CBF}$ mean velocity suggesting an increased risk of cerebral ischemia. The second study found that the alphastat strategy increased jugular vein desaturation and cerebral $\mathrm{O}_{2}$ extraction and decreased transcranial Doppler cerebral velocities in survivors but not in non-survivors.

In summary, dyscarbia especially hypocapnia should be associated with an increased harm after CA leading to increased unfavorable outcome or in-hospital mortality. Conversely $\mathrm{O}_{2}$ seems a two halves phenomenon with: (1) a former deleterious effect of hypoxia during resuscitation efforts, the potential benefit of hyperoxia implying more evaluations; (2) followed by a deleterious effect of both hypoxia and hyperoxia after ROSC in the post-CA phase. To date because $\mathrm{O}_{2}$ and $\mathrm{CO}_{2}$ derangements have no obvious benefit, aiming at normoxia and normocapnia 
after CA are potentially two very easy targets to achieve in post-resuscitation care bundles. Meanwhile all studies describing ABG parameters in TTM- or TH-treated CA patients should actually emphasize the strategy used, either a temperature-corrected or a non-corrected strategy to more precisely evaluate potential thresholds.

\section{Other means of cardio- and neuro-protection}

Fabio Taccone Heart and brain protection strategies aim to prevent or attenuate disease progression and secondary injuries by halting or at least slowing the loss of cardiomyocytes and/or neurons [111]. Although many pathological mechanisms, including endothelial damage and tissue hypoperfusion, inflammation, impaired mitochondrial respiration with induction of reactive oxygen species, calcium overload or excitotoxicity, are common in both cardiac and neurological injury following CA [112], some drugs may present a more specific organ protection or have a lower brain penetration, thus acting especially on the cardiac tissue. Many therapeutic agents have been shown to be effective in protecting the heart and/or the brain in animal models of global or local ischemia [113]; nevertheless, these findings were flawed because of the differences between the experimental setting and the clinical scenario (i.e. absence of co-morbid diseases and need for anesthetics in animal studies), the low mortality rates or the administration of the specific drug before the development of injury (i.e. pre-treatment approach).

A promising approach to reduce brain excitotoxicity (i.e. excessive extracellular glutamate levels) could be the administration of intravenous magnesium or inhaled noble gases (i.e. xenon or argon). In two studies, magnesium administration did not result in a better survival or neurological outcome for CA patients [114, 115]. However, hypothermia was not used in these studies, while the combination of magnesium with cooling procedures has been shown to result in the highest neuroprotective effects [116]. Importantly, many questions remain unanswered on the optimal timing to initiate magnesium perfusion, optimal dosing and circulating levels and potential side-effects, which may explain the negative results of magnesium therapy after subarachnoid hemorrhage and traumatic brain injury $[117,118]$. Noble gases have been proved to reduce the extent of neurological damage after ischemia in animal models of CA $[119,120]$. The administration of Xenon was also feasible in the human setting, reporting both no adverse events and an improvement of cardiovascular function after CA [121]. Unfortunately, we still do not have any human data describing the potential neurological benefits of such treatment.

Mitochondrial dysfunction could be attenuated by the administration of erythropoietin (EPO), the principal hematopoietic hormone regulating erythropoiesis, which shows also anti-apoptotic, anti-inflammatory and anti-oxidant properties [122]. In a swine model of VF, high-dose EPO administration during CPR reduced post-resuscitation myocardial dysfunction and improved cardiac function [123]. However, post-ischemic EPO administration in rats exposed to CA exerted no protective effect on hippocampal neurons [124]. One human study has compared the effects of $90.000 \mathrm{UI}$ of EPO given during CPR to an historical matched control group [125]. The EPO group had higher rates of ROSC ( 92 versus $53 \%, \mathrm{p}=0.006$ ) and hospital survival ( 54 versus $20 \%, \mathrm{p}=0.011$ ) when compared to the control group. In another study [126], EPO therapy was associated with a trend towards higher full neurological recovery (55 versus $38 \%$ ) when compared to an historical cohort. Unfortunately, a recent unpublished randomized clinical trial (RCT) found no benefits of EPO administration on comatose survivors after CA when compared to placebo (Cariou et al.-presented at the 27th ESICM congress-Barcelona, October 2014).

Reperfusion injury leads to mitochondrial dysfunction also through the opening of a nonspecific pore in the inner mitochondrial membrane, known as the mitochondrial permeability transition pore (MPTP) [127]. This phenomenon causes the loss of ionic homeostasis and ultimately cell swelling and death. The inhibition of the MPTP opening may provide some protection against reperfusion injury; importantly, this may be mediated by a direct interaction of cyclosporine A (CsA) with a protein located on the MPTP, called cyclophilin-D [127]. In a murine model of CA, CsA was effective in reducing myocardial dysfunction when given at the onset of resuscitation but not after ROSC [128]. In one human study conducted in patients suffering from acute myocardial infarction, the administration of a $2.5 \mathrm{mg} / \mathrm{kg}$ bolus of CsA before percutaneous coronary intervention was associated with a significant reduction in biomarkers of myocardial injury (i.e. troponin I) and the extent of ischemic areas on cardiac magnetic resonance imaging [129]. Nowadays, no clinical studies have evaluated the effects of CsA on the neurological recovery of CA survivors yet.

Also, mitochondrial dysfunction can be modulated through the nitric oxide (NO)-related pathways; NO inhibits ROS-producing enzymes and directly scavenges ROS production [130]. Other potential beneficial effects are the direct vasodilation of coronary arteries, which could improve cardiac function in this setting. Experimental models have suggested a protective role of intravenous NO-donors or inhaled NO both on cardiac and neurological function after CA [131, 132]. Unfortunately, only one pilot study showed the feasibility and safety of low-dose nitrite infusion in cardiac arrest survivors, but did not report any improvement in outcome [133]. 
Finally, recent data suggest that the early administration of corticosteroids after in-hospital CA was associated with an increased survival rate and reduced occurrence of extra-cerebral organ failures [134]; whether these effects were secondary to an anti-inflammatory effect or the treatment of a relative adrenal insufficiency [135], it remains to be further evaluated. Similarly, abnormalities of peripheral microcirculation, similar to those found in septic patients, have been described after CA [136]; the pathophysiology of such alterations as well as their role on patients' outcome and the various therapeutic options to manipulate the microvascular flow have to be better characterized in future studies.

\section{Neurological assessment of brain damages Minimal consciousness: classification and prognosis in CA patients}

Steven Laureys and Didier Ledoux Successful resuscitation after cardiac arrest or cerebral hypoxia can have an extremely wide variety of functional and cognitive consequences, ranging from transient cognitive or motor dysfunction lasting several weeks or months; to awakening after coma in a state of unawareness or inability to communicate lasting months to years or decades (e.g. as seen in vegetative or minimally conscious states) [137]. At present, the medical and economic impacts of differences in clinical management (including therapeutic hypothermia), care pathways and disparate health policies within Europe remain unclear.

Figure 8 illustrates the timeline of events that may occur after anoxic coma. When cerebral hypoxia leads to a prolonged loss of consciousness (lasting $>2$ h to differentiate from syncope), the patient is considered to be in coma. Patients in coma will never open the eyes, even if stimulated by a loud noise or intense noxious stimulus, and will only show reflex movements. Coma will not last longer than a couple of days to weeks. Most patients who show good recovery will rapidly show signs of consciousness and functional communication. Some patients, however, will evolve to brain death (i.e., irreversible coma with absent brainstem reflexes) and organ donation should be discussed [138]. Many patients will remain with some brainstem function (i.e., will not be brain death), but clinical and complimentary testing shows that there is no reasonable chance for a meaningful recovery and the decision is made to withhold or withdraw treatment. In these cases, organ donation after cardiac death can be discussed.

Patients who survive their coma may awaken (i.e., open the eyes) without any behavioural sign of consciousness (i.e., only show reflex or automatic movements), a condition coined "persistent vegetative state" or "unresponsive

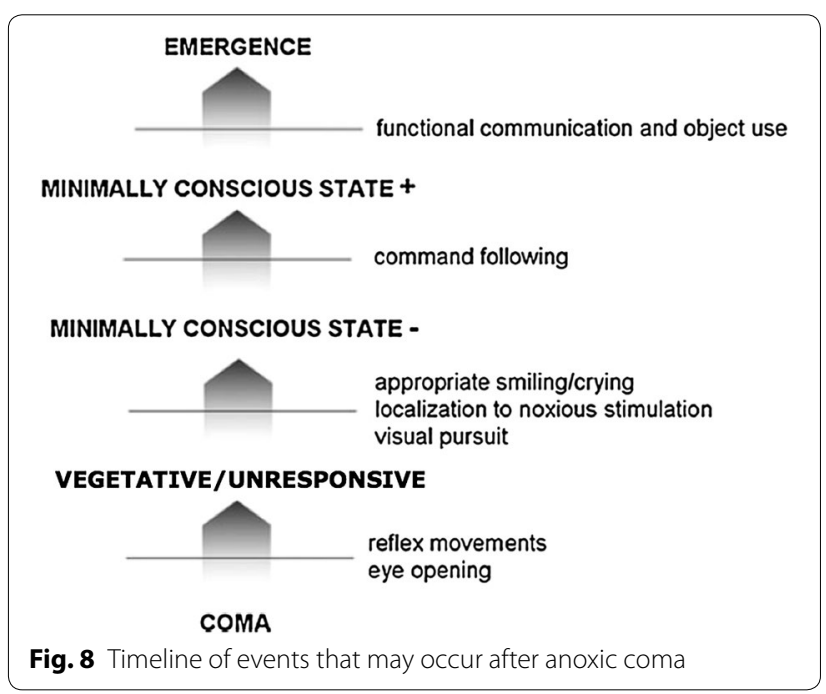

wakefulness syndrome" (PVS/UWS) [139] or without recovery of functional communication or functional object use, a condition referred to as "minimally conscious state" (MCS) [140]. In contrast to coma, such chronic disorders of consciousness can last for many months to years and at present there are no reliable epidemiological data regarding these challenging patients. The heterogeneous MCS group is subcategorized in MCS - when patients only show non-reflexive behaviour such as eye tracking, orientation to pain or contingent behaviour to specific stimuli (e.g. smiling exclusively in the presence of a family member) and MCS + when a reproducible (albeit often inconsistent) response to command can be observed [141].

When patients remain in PVS/UWS for over 3 months after the cardiac arrest, the condition is considered irreversible and life-sustaining treatment (i.e., artificial hydration and nutrition) may be considered as futile and hence be withdrawn. At present, the chances of recovery after post-anoxic MCS are considered to be better than for PVS/UWS but remain ill defined. Many patients who recover from coma or related disorders of consciousness will show cognitive dysfunction and may remain institutionalized or dependent of others for many activities of daily living, but few reliable data exist regarding their remaining quality of life.

Recent advances in automated clinical EEG analysis [142], combined EEG transcranial magnetic stimulation studies [143] and structural and functional neuroimaging have permitted to better document the clinical diagnosis [144] and levels of consciousness in patients with severe post-anoxic encephalopathy [145]. Several studies also show their value in predicting the chances of recovery after cardiac arrest (e.g., the assessment of EEG reactivity [142]; the quantification of white matter damage using 
MRI diffusion tensor imaging [146] or PET imaging of residual cortical metabolism [147].

At present, there are no evidence-based guidelines regarding the treatment of patients with chronic anoxic disorders of consciousness [148]. In terms of noninvasive intervention, transcranial direct current stimulation has recently been shown to be of potential interest [149]. A better understanding of the temporal dynamics of possible residual neural plasticity following anoxic coma and related conditions will permit to improve their clinical management (including treatment for possible pain perception [150]) and to rationalize our medical interventions [151] acute and chronic care pathways and endof-life decisions [152].

\section{Clinical tools}

Mauro Oddo The ideal tool for coma prognostication is the one yielding the lowest false-positive rate (FPR) for poor outcome. The definition of FPR is $1-$ specificity, whereby the "perfect" predictor would allow $100 \%$ (i.e. 1.0) specificity and an FPR for poor outcome of 0 and limit as far as possible the risk of false predictions. Clinical examination comprises tools for the assessment of neurological responses/reflexes, including the Glasgow Coma Scale (GCS), brainstem reflexes and the comprehensive Full Outline of Unresponsiveness (FOUR) score. Clinical examination is an essential step for coma prognostication after CA [153]. However, clinical examination may be misleading, partly because of the effect of mild induced hypothermia and sedation on neurological responses. In particular, using the motor component of the GCS, it was found that motor response to pain may be delayed up to 5-6 days following CA [154]. Motor reaction to pain no better than extension indeed yields an unacceptably high FPR (10-20\%) for poor prognosis [155]. Apart from GCS, the assessment of brainstem reflexes (pupillary and corneal reflexes in particular) is crucial. Corneal and pupillary reflexes have very high specificity: bilaterally absent pupillary/corneal reflexes yield an FPR $<1-2 \%$ for poor prognosis, while their FPR for good prognosis is relatively high (40-50\%) [155].

The predictive value of pupillary reactivity is underlined by recent systematic meta-analyses $[155,156]$. In this setting, newly available automated infrared pupillometers hold great promise, because they allow quantitative measurement of the pupillary response. One single-center study recently showed quantitative pupillometry is superior to standard pupillary examination for post-CA coma prognostication and performs comparably to electro-physiological exams (including EEG and SSEP) [157].

In summary, careful and complete neurological examination is the first and still valid tool for coma prognostication [158]. Clinical tools should be integrated into a multimodal approach, which ideally also include electrophysiology (EEG reactivity and/or SSEP) and blood biomarkers (e.g. NSE). Using this multimodal approach, prediction of 3-month survival and neurological outcome might approach $90 \%$ accuracy [159]. Application of such approach is supported by several recent independent studies and can be recommended in ICU practice [160].

\section{New electrophysiological tools: continuous and simplified electroencephalography (aEEG)}

Hans Friberg Electroencephalography (EEG) is a commonly used method for identification of seizures and for estimation of prognosis in comatose survivors after cardiac arrest [161]. Limitations with an EEG-investigation include its sensitivity to sedatives and the fact that a single conventional EEG depicts the actual status during a limited time, commonly 20-30 min. Another problem has been the lack of consensus regarding EEG terminology and the absence of a uniform classification system, a problem that may be resolved by implementation of a standardized critical care EEG-terminology as recently proposed [162].

EEG-patterns that are strongly associated with a poor outcome after cardiac arrest and considered "malignant patterns" include a generalized suppression to $<20 \mu \mathrm{V}$, burst-suppression pattern with generalized epileptiform activity, or generalized periodic complexes on a flat background [163]. In addition, a non-reactive EEG background pattern after rewarming from hypothermia treatment has been found to be a predictor of poor outcome [164]. A reactive EEG-pattern on the other hand, and a return of a continuous EEG background pattern after cardiac arrest are both strongly associated with recovery and a good outcome [163, 164].

Continuous EEG (cEEG) provides dynamic information and can be used to monitor evolution of EEG-patterns and to detect seizures in the postischemic brain [165]. A traditional multichannel montage is commonly used in adult ICUs, while a simplified EEG-montage with few channels and trend analysis is more common in neonatal ICUs [166]. In order to reach general use, cEEG needs to be simple, possible to apply bedside and cost-effective.

We applied aEEG in consecutive cardiac arrest patients [167]. The aEEG curve facilitates rapid surveillance of extended time periods, but interpretation of patterns is done on the original EEG-tracings, one from each hemisphere. The relative simplicity of cEEG with a reduced montage and aEEG trend analysis makes it attractive to generalists in the ICU. It is applied bedside by the ICUstaff (registered nurse) and data are linked to the neurophysiologists, who will assess the collected data on a 
regular basis and on demand. In order to facilitate for clinicians, four dominating EEG-patterns after cardiac arrest were identified and described (Fig. 9) [167]. Our experience is that cEEG with a simplified montage and aEEG trend analysis is well suited to follow transitions in background patterns and has acceptable sensitivity to detect clinically relevant electrographic seizures. A return of a continuous EEG-pattern at normothermia is an early and strong prognostic indicator with a positive-predictive value for a good outcome of 0.87 (95\% CI 0.76-0.94) while other patterns at normothermia indicate a poor prognosis with a negative predictive value of 0.91 ( $95 \%$ CI 0.76-0.98) [167]. The clinical benefit of treating electrographic seizure activity after cardiac arrest is yet to be proven, but simplified cEEG is a reasonable routine method to diagnose seizure activity and to guide treatment.

In conclusion, simplified continuous EEG (cEEG) with trend analysis (aEEG) is a feasible and probably costeffective method to improve care after cardiac arrest [168]. Collaboration with neurologists and neurophysiologists and education of staff are keys to success. We foresee that simplified cEEG will be part of routine bedside monitoring of comatose survivors after cardiac arrest in the near future.

\section{Neurological assessment in the long-term follow-up after cardiac arrest}

Stephane Legriel Half the survivors after CA have long-term follow-up cognitive impairment affecting pref- erentially memory and executive functioning, anxiety, depression, and finally quality of life. Surprisingly, there is no prospective study with extensive neuropsychological assessment and longitudinal follow-up allowing to confirm these retrospective data [169]. Moreover, the era of therapeutic hypothermia may have changed not only long-term outcomes, but also its early prognosis assessment [170]. Thus, three important questions can be raised.

What tools do we use to describe the long-term outcome and are these tools sensitive? Whereas a recent review demonstrated a broad heterogeneity in the outcome measures utilized in clinical trials, the Cerebral Performance Category (CPC) score is the recommended measurement of long-term outcome after CA [170]. The question of reliability of the CPC score has been evaluated in several studies. There was a strong association between the CPC score at hospital discharge and longterm outcome. Moreover, the CPC score demonstrated good correlation with various neuropsychological evaluations in extensive cognitive battery tests, memory tests, adaptative behavior and quality-of-life evaluations. Thus the CPC could be considered as a gross indicator of longterm functional outcome after $\mathrm{CA}$.

How could we evaluate the outcome during the longterm follow up? According to the World Health Organization guidelines, evaluation of health after CA should associate body functions and structures, with physical examination and cognitive functions, activity and participation, personal factors such as anxiety and depression,
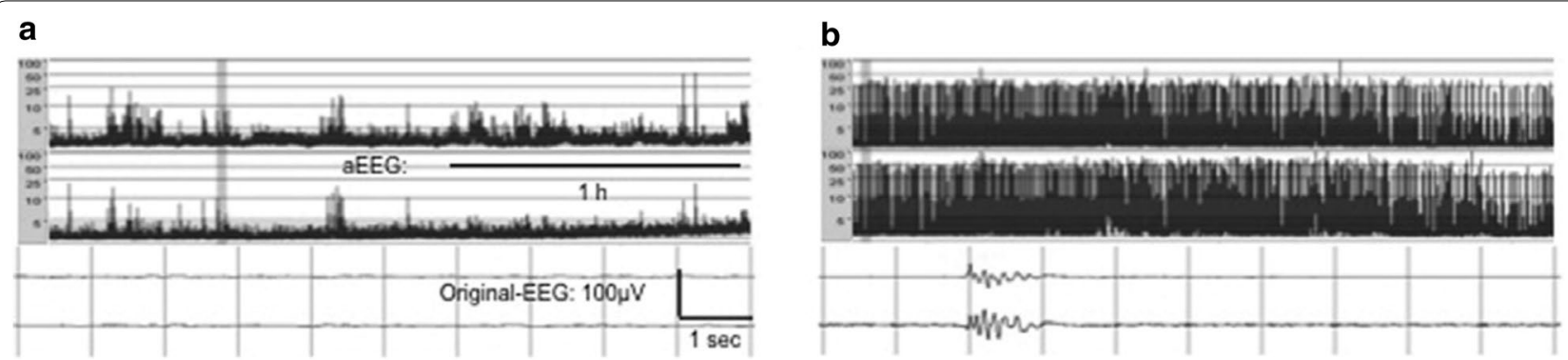

C

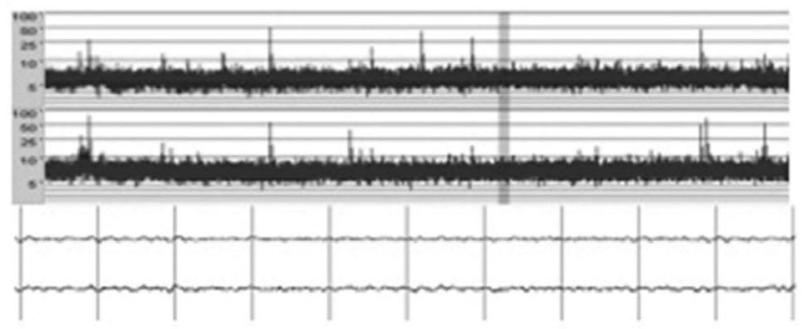

d

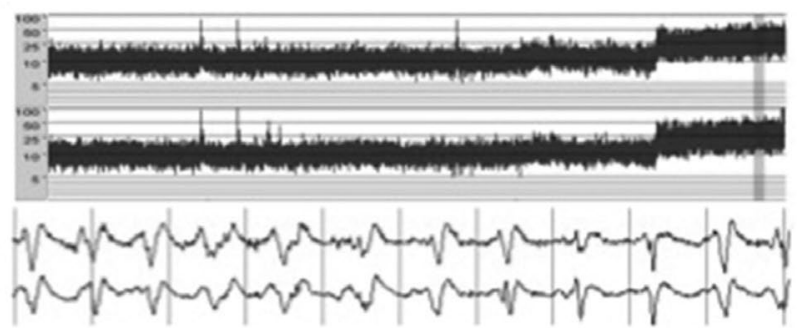

Fig. 9 A simplified electroencephalogram (EEG) with two original EEG curves (lower pane), in combination with an amplitude integrated EEG (aEEG) trend curve (upper panel). Four dominating EEG patterns after cardiac arrest are shown: a flat, b suppression-burst, c continuous and $\mathbf{d}$ electrographic status epilepticus. From Friberg et al. [161]. Reprinted with permission 
and so quality of life (Fig. 10) [171, 172]. The American Academy of Clinical Neuropsychology recently recommended evaluation of the following items during a neuropsychological evaluation: intellectual functioning, attention and executive functioning, memory and learning, language and communication, visual-spatial cognition and visual-motor praxis, motor and sensory function, mood, conduct, personality, quality of life, adaptative behavior (activities of daily living), socialemotional awareness and responsivity, psychopathology (psychotic thinking or somatization), motivation and effort [173]. Thereby, a formal neuropsychological evaluation covers the whole spectrum of objectives of health evaluation.

What approach should we use to make an early prognosis of long-term outcome? All the parameters provided in 2006 by the American Academy of Neurology for prediction of outcome in comatose survivors after cardiopulmonary resuscitation have been challenged since the application of therapeutic hypothermia. Predictors based on clinical examination within $72 \mathrm{~h}$ after CA have demonstrated higher false-positive rates [164]. Exceptional survivors have been described despite bilateral absence of N20 waves in median nerve somatosensory evoked potentials. Neuron Specific Enolase demonstrated variable cut-off values associated with poor outcome ranging from 25 to $49.5 \mathrm{ng} / \mathrm{mL}$ on day 2 after cardiac arrest, with one survivor with an NSE value of $110 \mathrm{ng} / \mathrm{mL}$. On day 3, variability was greater ranging from 10.6 to $97 \mathrm{ng} / \mathrm{mL}$. Protein S100B was also associated with variability on day 1 after CA [156]. Postanoxic status epilepticus has been demonstrated as an independent factor associated with poor outcome in retrospective and prospective studies

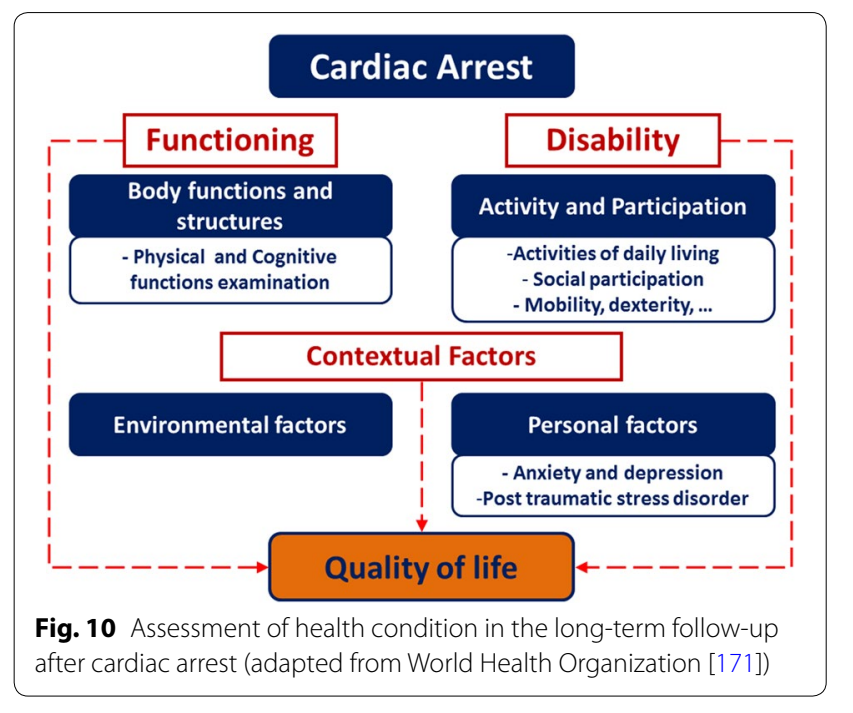

[174, 175], but survivors with good long-term functional outcome have been described in $6 \%$ of cases [175]. Continuous background pattern and reactivity during $\mathrm{TH}$ or normothermia has been associated with recovery and EEG plays now an increasingly important role in prognostication of coma after CA. Thus, continuous EEG has been suggested to assist with prognostication of coma after CA [176]. Finally, literature data clearly favour a multimodal approach of prognostication after CA.

In conclusion, there is a broad variability in tools used for evaluation during the long-term follow and a lack of standardization. The cerebral performance category scale is an efficient but imperfect surrogate tool to describe long-term outcome after CA. The neuropsychological evaluation seems able to cover the whole spectrum of objectives of health evaluation needed to evaluate the long-term outcome. Early prognosis of long-term outcome at the era of therapeutic hypothermia should be based on a multimodal approach in order to minimize false predictions.

\section{Public healthcare}

Stopping cares leads to organ donation?

Philippe Hantson There is still currently a shortage of organs for transplantation and accordingly, different strategies have been developed, including the possibility of organ donation after cardiocirculatory death (DCD) as opposed to donation after brain death (DBD). Following the Maastricht workshop on non-heart beating donation in 1995, several categories of donors have been identified, but the acceptance of such procedures still varies largely among the different European countries. There is no doubt that the ratio DCD/DBD will continue to increase over time.

The ICUs are mainly concerned by categories II (unsuccessful resuscitation) and III (awaiting cardiac arrest). Category III is a controllable situation that could be managed either in the ICU or in the operating room. The possibility of organ donation under category III is also linked to ethical discussions regarding the management of the "end of life", with a clear distinction between the concepts of euthanasia and withdrawal/withholding of some specific cares [177].

In contrast to DBD where specific protocols are now well accepted, there is a great variability for the DCD protocols regarding the criteria for the determination of death, but also for the definition of the "no-touch" period. This latter corresponds to the time period between determination of death and initiation of organ procurement, and should be theoretically kept as short as possible in order to prevent warm ischemia. 
The main ethical difficulties are related to the perceived possibility of conflict of interest for the ICU physician who in one hand could take the decision to withdraw or withhold some specific care, and in a next step could also be authorized to take the decision of organ donation in the same patient. The separation (in time and space) between the two processes is absolutely mandatory. There is a need of full confidence between all the members of the ICU staff taking care of the patient, so that each individual could be convinced that the treatmentwithdrawal decision is always made independently from any considerations about the potential of subsequent organ donation.

Another difficult ethical issue is the dying process itself. It remains difficult to predict the time to death by circulatory arrest after the withdrawal of the life-sustaining treatments. When organ donation is not considered, the patient is dying in the ICU, while in case of DCD, death will occur in the operating room, with ideally a short period of hypotension in order to prevent organ damages. But in fact, the dying process has already started several hours or days before the final decision in the ICU. The vision that the DCD procedure could hasten the patient's death is not totally true, but there are still different perceptions among the ICU physicians. Some of them feel that when comfort therapy with potent sedatives and analgesics ("palliative sedation") is started in the ICU, the priority is to give a lot of time to the family to accompany the dying person. Other ICU physicians or even scientific societies consider that shortening the dying process with use of medications may sometimes be appropriate, even in the absence of discomfort, and can actually improve the quality of dying. Most of the families express the opinion that the priority should be that the patient would die peacefully, the duration of the dying process being of secondary importance. This is a key issue in the debate "taking care of the patient or taking care of the organs?" [178].

Finally, the wishes expressed by the patient (anticipatively) or by the relatives have clearly to be taken into account. The treatment-withdrawal modalities will clearly be also be influenced by these opinions. When the decision is made to stop the cares in the operating room, it is with the objective that cardiocirculatory death would occur in a delay shorter than one hour and that the procedure of donation would be successful.

In conclusion, organ procurement under Maastricht III category will remain a sensitive issue as no protocol is widely accepted. Each centre has the responsibility to initiate the debate between all the participants involved in critical care and organ transplantation. The main perceived risk is the abolition of the frontier between the cares orientated to the patient and the cares given to the organs.

\section{Abbreviations}

aEEG: continuous and simplified EEG-montage with two channels in combination with amplitude integrated trend analysis; AED: automated external defibrillators; ALS: advanced life support; BLS: basic life support; CA: cardiac arrest; CCPR: conventional CPR; CEEG: continuous electroencephalography; CPR: cardio-pulmonary resuscitation; DBD: donation after brain death; DCD donation after cardiocirculatory death; DNAR: do-not-attempt-resuscitation; ECPR: extracorporeal CPR; EMS: emergency medical services; ETI: endotracheal intubation; FOUR: full outline of unresponsiveness; GCS: Glasgow coma score; ICU: intensive care unit; IHCA: in-hospital cardiac arrest; MCS: minimally conscious state; MET: medical emergency team; MTH: mild therapeutic hypothermia; NIRS: near-infrared spectrophotometry; OHCA: out-hospital-cardiac arrest; $\mathrm{PCl}$ : percutaneous coronary intervention; PE: pulmonary embolism; PEA: pulseless electrical activity; PVS: persistent vegetative state; ROSC: return of spontaneous circulation; RRS: rapid response systems; TH: therapeutic hypothermia; TTM: targeted temperature management; UWS: unresponsive wakefulness syndrome; VF: ventricular fibrillation; WLST: withdrawal of lifesustaining therapy.

\section{Authors' contributions}

PFL and JLD were responsible for the organization of the meeting, for the collection of the summaries, and for the redaction of the Introduction and Conclusion sections, as well as for structuring the Review. PJK, CS, HRD, BWB, $A C, K S, M D, F S T, N D, H F, S L, D L, M O, S L$, and $P H$ were responsible for individual presentation and for redaction of the corresponding summaries. All authors read and approved the final manuscript.

\section{Author details}

${ }^{1}$ University of Washington, Seattle, USA. ${ }^{2}$ Department of Anaesthesiology and Intensive Care, Catholic University School of Medicine, Rome, Italy. ${ }^{3}$ Department of Anaesthesiology and Intensive Care Medicine, University of Koeln, Cologne, Germany. ${ }^{4}$ Medical Intensive Care Unit, AP-HP, Cochin Hospital, Paris, France. ${ }^{5}$ Paris Descartes University and Sorbonne Paris Cité-Medical School and INSERM U970 (Team 4), Cardiovascular Research Center, European Georges Pompidou Hospital, Paris, France. ${ }^{6}$ Division of Emergencies and Critical Care, Department of Anaesthesiology, Surgical Intensive Care Unit Ullevål, Oslo University Hospital, Oslo, Norway. ${ }^{7}$ Division of Cardiothoracic and Vascular Anesthesia and Intensive Care Medicine, Vienna General Hospital, Medical University Vienna, Vienna, Austria. ${ }^{8}$ Department of Intensive Care, Laboratoire de Recherche Experimentale, Erasme Hospital, Brussels, Belgium. ${ }^{9}$ Medical Intensive Care Unit, AP-HP, Lariboisière University Hospital, Inserm U942, Paris, France. ${ }^{10}$ Anaesthesiology and Intensive Care Medicine, Skåne University Hospital, Lund University, Lund, Sweden. ${ }^{11}$ Coma Science Group, Cyclotron Research Centre, University of Liège and Liège 2 Department of Neurology, University Hospital of Liège, Liège, Belgium. ${ }^{12}$ Coma Science Group, Cyclotron Research Centre, University of Liège and Department of Intensive Care Medicine, University Hospital of Liège, Liège, Belgium. ${ }^{13}$ Department of Intensive Care Medicine, Faculty of Biology and Medicine, CHUV-University Hospital, Lausanne, Switzerland. ${ }^{14}$ Intensive Care Unit, Centre Hospitalier de Versailles, Le Chesnay, France. ${ }^{15}$ Department of Intensive Care, Cliniques Universitaires Saint-Luc, Université Catholique de Louvain, Brussels, Belgium. ${ }^{16}$ Medical Intensive Care Unit, AP-HP, European Georges Pompidou Hospital, Paris Descartes University and Sorbonne Paris Cité-Medical School, Paris, France.

${ }_{17}$ Department of Intensive Care, Cliniques Universitaires Saint-Luc, Université Catholique de Louvain Brussels, Brussels, Belgium.

\section{Compliance with ethical guidelines}

\section{Competing interests}

Hans Friberg has received lecture fees from Natus Inc. The other authors reported no competing interests.

Received: 5 March 2015 Accepted: 18 August 2015

Published online: 17 September 2015 


\section{References}

1. Cobb LA, Fahrenbruch CE, Olsufka M, Copass MK. Changing incidence of out-of-hospital ventricular fibrillation, 1980-2000. JAMA. 2002;288:3008-13.

2. Go AS, Mozaffarian D, Roger VL, Benjamin EJ, Berry JD, Blaha MJ, Dai S, Ford ES, Fox CS, Franco S, Fullerton HJ, Gillespie C, Hailpern SM, Heit JA Howard VJ, Huffman MD, Judd SE, Kissela BM, Kittner SJ, Lackland DT, Lichtman JH, Lisabeth LD, Mackey RH, Magid DJ, Marcus GM, Marelli A, Matchar DB, McGuire DK, Mohler ER 3rd, Moy CS, Mussolino ME, Neumar RW, Nichol G, Pandey DK, Paynter NP, Reeves MJ, Sorlie PD, Stein J, Towfighi A, Turan TN, Virani SS, Wong ND, Woo D, Turner MB, American Heart Association Statistics Committee and Stroke Statistics Subcommittee. Heart disease and stroke statistics-2014 update. Circulation. 2014;129:e28-292.

3. Beredowski J, Berg RA, Tijsse JGP, Koster RW. Global incidences of outof-hospital cardiac arrest and survival rates: systematic review of 67 prospective studies. Resuscitation. 2010;81:1479-87.

4. Dumas F, Cariou A, Manzo-Silberman S, Grimaldi D, Vivien B, Rosencher J, Empana JP, Carli P, Mira JP, Jouven X, Spaulding C. Immediate percutaneous coronary intervention is associated with better survival after out-of-hospital cardiac arrest: insights from the PROCAT (Parisian Region Out of Hospital Cardiac Arrest) Registry. Circ Cardiovasc Interv. 2010;3:200-7.

5. Nichol G, Thomas E, Callaway CW, Hedges J, Powell JL, Aufderheide TP, Rea T, Lowe R, Brown T, Dreyer J, Davis D, Idris A, Stiell I, Resuscitation Outcomes Consortium Investigators. Regional variation in out-of-hospital cardiac arrest incidence and outcome. JAMA. 2008;300:1423-31.

6. Nichol G, Rumsfeld J, Eigel B, Abella BS, Labarthe D, Hong Y, O'Connor RE, Mosesso VN, Berg RA, Leeper BB, Weisfeldt ML, American Heart Association Emergency Cardiovascular Care Committee, American Heart Association Council on Cardiopulmonary, Perioperative, and Critical Care, American Heart Association Council on Cardiovascular Nursing, American Heart Association Council on Clinical Cardiology, Quality of Care and Outcomes Research Interdisciplinary Working Group. Essential features of designating out-of-hospital cardiac arrest as a reportable event: a scientific statement from the American Heart Association Emergency Cardiovascular Care Committee; Council on Cardiopulmonary, Perioperative, and Critical Care; Council on Cardiovascular Nursing; Council on Clinical Cardiology; and Quality of Care and Outcomes Research Interdisciplinary Working Grou. Circulation. 2008;117:2299-308.

7. Rea TD, Helbock M, Perry S, Garcia M, Cloyd D, Becker L, Eisenberg M. Increasing use of cardiopulmonary resuscitation during out-of-hospital ventricular fibrillation arrest: survival implications of guideline changes. Circulation. 2006;114:2760-5.

8. Kudenchuk P, Redshaw JD, Stubbs BA, Fahrenbruch CE, Dumas F, Phelps R, Blackwood J, Rea TD, Eisenberg MS. Impact of changes in resuscitation practice on survival and neurological outcome after out-of-hospital cardiac arrest resulting from nonshockable arrhythmias. Circulation. 2012:125:1787-94

9. Sandroni C, Nolan J, Cavallaro F, Antonelli M. In-hospital cardiac arrest: incidence, prognosis and possible measures to improve survival. Intensive Care Med. 2007;33:237-45.

10. DeVita MA, Smith GB, Adam SK, Adams-Pizarro I, Buist M, Bellomo R, Bonello R, Cerchiari E, Farlow B, Goldsmith D, Haskell H, Hillman K, Howell M, Hravnak M, Hunt EA, Hvarfner A, Kellett J, Lighthall GK, Lippert A, Lippert FK, Mahroof R, Myers JS, Rosen M, Reynolds S, Rotondi A, Rubulotta F, Winters B. "Identifying the hospitalised patient in crisis" - a consensus conference on the afferent limb of rapid response systems. Resuscitation. 2010;81:375-82.

11. Chalfin DB, Trzeciak S, Likourezos A, Baumann BM, Dellinger RP. Impact of delayed transfer of critically ill patients from the emergency department to the intensive care unit. Crit Care Med. 2007;35:1477-83.

12. Chan PS, Khalid A, Longmore LS, Berg RA, Kosiborod M, Spertus JA. Hospital-wide code rates and mortality before and after implementation of a rapid response team. JAMA. 2008;300:2506-13.

13. Chan PS, Jain R, Nallmothu BK, Berg RA, Sasson C. Rapid response teams: a systematic review and meta-analysis. Arch Intern Med. 2010;170:18-26
14. Hillman K, Chen J, Cretikos M, Bellomo R, Brown D, Doig G, Finfer S, Flabouris A. Introduction of the medical emergency team (MET) system: a cluster-randomised controlled trial. Lancet. 2005;365:2091-7.

15. Sandroni C, Cavallaro F. Failure of the afferent limb: a persistent problem in rapid response systems. Resuscitation. 2011;82:797-8.

16. Wnent J, Bohn A, Seewald S, Fischer M, Messelken M, Jantzen T, Gräsner I, Gräsner JT. Bystander resuscitation: the impact of first aid on survival. Anasthesiol Intensivmed Notfallmed Schmerzther. 2013;48:562-5.

17. Wissenberg M, Lippert FK, Folke F, Weeke P, Hansen CM, Christensen EF, Jans H, Hansen PA, Lang-Jensen T, Olesen JB, Lindhardsen J, Fosbol EL, Nielsen SL, Gislason GH, Kober L, Torp-Pedersen C. Association of national initiatives to improve cardiac arrest management with rates of bystander intervention and patient survival after out-of-hospital cardiac arrest. JAMA. 2013;310:1377-84.

18. Stiell IG, Brown SP, Christenson J, Cheskes S, Nichol G, Powell J, Bigham B, Morrison L, Larsen J, Hess E, Vaillancourt C, Davis DP, Callaway CW, Resuscitation Outcomes Consortium (ROC) Investigators. What is the role of chest compression depth during out-of-hospital cardiac arrest resuscitation? Crit Care Med. 2012;40:1192-8.

19. Idris AH, Guffey D, Aufderheide TP, Brown S, Morrison LJ, Nichols P, Powell J, Daya M, Bigham BL, Atkins DL, Berg R, Davis D, Stiell I, Sopko G, Nichol G, Resuscitation Outcomes Consortium (ROC) Investigators. Relationship between chest compression rates and outcomes from cardiac arrest. Circulation. 2012;125:3004-12.

20. Berg RA, Sanders AB, Kern KB, Hilwig RW, Heidenreich JW, Porter ME, Ewy GA. Adverse hemodynamic effects of interrupting chest compressions for rescue breathing during cardiopulmonary resuscitation for ventricular fibrillation cardiac arrest. Circulation. 2001;104:2465-70.

21. Jennings PA, Cameron P, Walker T, Bernard S, Smith K. Out-of-hospital cardiac arrest in Victoria: rural and urban outcomes. Med J Aust. 2006;185:135-9.

22. Wang HE, Szydlo D, Stouffer JA, Lin S, Carlson JN, Vaillancourt C, Sears G, Verbeek RP, Fowler R, Idris AH, Koenig K, Christenson J, Minokadeh A, Brandt J, Rea T, ROC Investigators. Endotracheal intubation versus supraglottic airway insertion in out-of-hospital cardiac arrest. Resuscitation. 2012;83:1061-6.

23. Hagihara A, Hasegawa M, Abe T, Nagata T, Nabeshima Y. Physician presence in an ambulance car is associated with increased survival in out-of-hospital cardiac arrest: a prospective cohort analysis. PLoS One. 2014;9:e84424.

24. Fischer M, Krep H, Wierich D, Heister U, Hoeft A, Edwards S, CastrilloRiesgo LG, Krafft T. Comparison of the emergency medical services systems of Birmingham and Bonn: process efficacy and cost effectiveness. Anasthesiol Intensivmed Notfallmed Schmerzther. 2003:38:630-42.

25. Nolan JP, Neumar RW, Adrie C, Aibiki M, Berg RA, Böttiger BW, Callaway C, Clark RS, Geocadin RG, Jauch EC, Kern KB, Laurent I, Longstreth WT, Merchant RM, Morley P, Morrison LJ, Nadkarni V, Peberdy MA, Rivers EP, Rodriguez-Nunez A, Sellke FW, Spaulding C, Sunde K, Hoek TV. Postcardiac arrest syndrome: epidemiology, pathophysiology, treatment and prognostication. A Scientific Statement from the International Liaison Committee on Resuscitation; the American Heart Association Emergency Cardiovascular Care Committee; the Council on Cardiovascular Surgery and Anesthesia; the Council on Cardiopulmonary, Perioperative, and Critical Care; the Council on Clinical Cardiology; the Council on Stroke. Resuscitation. 2008:79:350-79.

26. Spaulding CM, Joly LM, Rosenberg A, Monchi M, Weber SN, Dhainaut JF, Carli P. Immediate coronary angiography in survivors of out-of-hospital cardiac arrest. N Engl J Med. 1997;336:1629-33.

27. Strote JA, Maynard C, Olsufka M, Nichol G, Copass MK, Cobb LA, Kim F. Comparison of role of early (less than six hours) to later (more than six hours) or no cardiac catheterization after resuscitation from out-ofhospital cardiac arrest. Am J Cardiol. 2012;109:451-4.

28. Hollenbeck RD, McPherson JA, Mooney MR, Unger BT, Patel NC, McMulIan PW Jr, Hsu CH, Seder DB, Kern KB. Early cardiac catheterization is associated with improved survival in comatose survivors of cardiac arrest without STEMI. Resuscitation. 2014;85:88-95.

29. Wolfrum S, Pierau C, Radke PW, Schunkert H, Kurowski V. Mild therapeutic hypothermia in patients after out-of-hospital cardiac arrest due to acute ST-segment elevation myocardial infarction undergoing immediate percutaneous coronary intervention. Crit Care Med. 2008;36:1780-6. 
30. Gräsner JT, Meybohm P, Caliebe A, Böttiger BW, Wnent J, Messelken M, Jantzen T, Zeng T, Strickmann B, Bohn A, Fischer H, Scholz J, Fischer M, German Resuscitation Registry Study Group. Postresuscitation care with mild therapeutic hypothermia and coronary intervention after out-ofhospital cardiopulmonary resuscitation: a prospective registry analysis. Crit Care. 2011;15:R61.

31. Dumas F, White L, Stubbs BA, Cariou A, Rea TD. Long-term prognosis following resuscitation from out of hospital cardiac arrest: role of percutaneous coronary intervention and therapeutic hypothermia. J Am Coll Cardiol. 2012;60:21-7.

32. Diao M, Huang F, Guan J, Zhang Z, Xiao Y, Shan Y, Lin Z, Ding L. Prehospital therapeutic hypothermia after cardiac arrest: a systematic review and meta-analysis of randomized controlled trials. Resuscitation. 2013;84:1021-8.

33. Kim F, Nichol G, Maynard C, Hallstrom A, Kudenchuk PJ, Rea T, Copass MK, Carlbom D, Deem S, Longstreth WT Jr, Olsufka M, Cobb LA. Effect of prehospital induction of mild hypothermia on survival and neurological status among adults with cardiac arrest: a randomized clinical trial. JAMA. 2014;311:45-52.

34. Sunde K. SOPs and the right hospitals to improve outcome after cardiac arrest. Best Pract Res Clin Anaesthesiol. 2013;27:373-81.

35. Chelly J, Mongardon N, Dumas F, Varenne O, Spaulding C, Vignaux O, Carli P, Charpentier J, Pène F, Chiche J-D, Mira J-P, Cariou A. Benefit of an early and systematic imaging procedure after cardiac arrest: insights from the PROCAT (Parisian Region Out of Hospital Cardiac Arrest) registry. Resuscitation. 2012;83:1444-50.

36. Deakin CD, Morrisson LJ, Morley PT, Callaway CW, Kerber RE, Kronick SL, Lavonas EJ, Link MS, Neumar RW, Otto CW, Parr M, Shuster M, Sunde K, Peberdy MA, Tang, W, Vanden Hoeck TL, Böttiger BW, Drajer S, Lim SH, Nolan JP, Advanced Life Support Chapter Collaborators. Part 8: advanced life support: 2010 international consensus on cardiopulmonary resuscitation and emergency cardiovascular care science with treatment recommendations. Resuscitation. 2010;81S:e93-174.

37. Böttiger BW, Arntz HR, Chamberlain DA, Bluhmki E, Belmans A, Danays T, Carli PA, Adgey JA, Bode C, Wenzel V, TROICA Trial Investigators, European Resuscitation Council Study Group. Thrombolysis during resuscitation for out-of-hospital cardiac arrest. N Engl J Med. 2008;359:2651-62.

38. Böttiger BW, Böhrer H, Bach A, Motsch J, Martin E. Bolus injection of thrombolytic agents during cardiopulmonary resuscitation for massive pulmonary embolism. Resuscitation. 1994;28:45-54.

39. Böttiger BW, Martin E. Thrombolytic therapy during cardiopulmonary resuscitation and the role of coagulation activation after cardiac arrest. Curr Opin Crit Care. 2001;7:176-83.

40. Böttiger BW, Bode C, Kern S, Gries A, Gust R, Glätzer R, Bauer H, Motsch J, Martin E. Efficacy and safety of thrombolytic therapy after initially unsuccessful cardiopulmonary resuscitation: a prospective clinical trial. Lancet. 2001;357:1583-5.

41. Lederer W, Lichtenberger C, Pechlaner C, Kroesen G, Baubin M. Recombinant tissue plasminogen activator during cardiopulmonary resuscitation in 108 patients with out-of-hospital cardiac arrest. Resuscitation. 2001;50:71-6.

42. Nolan JP, Soar J, Zideman DA, Biarent D, Bossaert LL, Deakin C, Koster RW, Wyllie J, Böttiger B, ERC Guidelines Writing Group. European resuscitation council guidelines for resuscitation 2010 section 1. Executive summary. Resuscitation. 2010;81:1219-76.

43. Nolan JP, Perkins GD. Is there a role for adrenaline during cardiopulmonary resuscitation? Curr Opin Crit Care. 2013;19:169-74.

44. Reynolds JC, Frisch A, Rittenberger J, Callaway C. Duration of resuscitation efforts and functional outcome after out-of-hospital cardiac arrest: when should we change to novel therapies? Circulation. 2013;128:2488-94.

45. Kitamura T, Iwami T, Kawamura T, Nagao K, Tanaka H, Berg RA, Hiraide A, Implementation Working Group for All-Japan Utstein Registry of the Fire and Disaster Management Agency. Time-dependent effectiveness of chest compression-only and conventional cardiopulmonary resuscitation for out-of-hospital cardiac arrest of cardiac origin. Resuscitation. 2011;82:3-9.

46. Tanno K, Itoh Y, Takeyama Y, Nara S, Mori K, Asai Y. Utstein style study of cardiopulmonary bypass after cardiac arrest. Am J Emerg Med. 2008;26:649-54.
47. Paden ML, Conrad SA, Rycus PT, Thiagarajan RR, ELSO Registry Extracorporeal life support organization registry report 2012. ASAIO J. 2013;59:202-10.

48. Centers for Disease Control and Prevention. Morbidity and mortality weekly report. Surveill Summ. 2011;60:8.

49. Chen YS, Lin JW, Yu HY, Ko WJ, Jerng JS, Chang WT, Chen WJ, Huang SC, Chi NH, Wang CH, Chen LC, Tsai PR, Wang SS, Hwang JJ, Lin FY. Cardiopulmonary resuscitation with assisted extracorporeal life-support versus conventional cardiopulmonary resuscitation in adults with inhospital cardiac arrest: an observational study and propensity analysis. Lancet. 2008;372:554-62.

50. Cave DM, Gazmuri RJ, Otto CW, Nadkarni VM, Cheng A, Brooks SC, Daya M, Sutton RM, Branson R, Hazinski MF. Part 7: CPR techniques and devices: 2010 American heart association guidelines for cardiopulmonary resuscitation and emergency cardiovascular care. Circulation. 2010;122:S720-8.

51. Nagao K, Kikushima K, Watanabe K, Tachibana E, Tominaga Y, Tada K, Ishii M, Chiba N, Kasai A, Soga T, Matsuzaki M, Nishikawa K, Tateda Y, Ikeda H, Yagi T. Early induction of hypothermia during cardiac arrest improves neurological outcomes in patients with out-of-hospital cardiac arrest who undergo emergency cardiopulmonary bypass and percutaneous coronary intervention. Circ J. 2010;74:77-85.

52. Holzer M. Targeted temperature management for comatose survivors of cardiac arrest. N Engl J Med. 2010;363:1256-64.

53. Bernard SA, Smith K, Cameron P, Masci K, Taylor DM, Cooper DJ, Kelly AM, Silvester W, Rapid Infusion of Cold Hartmanns Investigators. Induction of prehospital therapeutic hypothermia after resuscitation from nonventricular fibrillation cardiac arrest. Crit Care Med. 2012;40:747-53.

54. Kim F, Olsufka M, Carlbom D, Deem S, Longstreth WT Jr, Hanrahan M, Maynard C, Copass MK, Cobb LA. Pilot study of rapid infusion of $2 L$ of 4 degrees $C$ normal saline for induction of mild hypothermia in hospitalized, comatose survivors of out-of-hospital cardiac arrest. Circulation. 2005; 112:715-9.

55. Kliegel A, Janata A, Wandaller C, Uray T, Spiel A, Losert H, Kliegel M, Holzer M, Haugk M, Sterz F, Laggner AN. Cold infusions alone are effective for induction of therapeutic hypothermia but do not keep patients cool after cardiac arrest. Resuscitation. 2007;73:46-53.

56. Yannopoulos D, Zviman M, Castro V, Kolandaivelu A, Ranjan R, Wilson RF, Halperin HR. Intra-cardiopulmonary resuscitation hypothermia with and without volume loading in an ischemic model of cardiac arrest. Circulation. 2009;120:1426-35.

57. Hoedemaekers CW, Ezzahti M, Gerritsen A, van der Hoeven JG. Comparison of cooling methods to induce and maintain normo- and hypothermia in intensive care unit patients: a prospective intervention study. Crit Care. 2007;11:R91.

58. Taccone FS, Donadello K, Beumier M, Scolletta S. When, where and how to initiate hypothermia after adult cardiac arrest. Minerva Anestesiol. 2011;77:927-33.

59. Merchant RM, Abella BS, Peberdy MA, Soar J, Ong ME, Schmidt GA, Becker LB, Vanden Hoek TL. Therapeutic hypothermia after cardiac arrest: unintentional overcooling is common using ice packs and conventional cooling blankets. Crit Care Med. 2006;34:S490-4.

60. Uray T, Haugk M, Sterz F, Arrich J, Richling N, Janata A, Holzer M, Behringer W. Surface cooling for rapid induction of mild hypothermia after cardiac arrest: design determines efficacy. Acad Emerg Med. 2010;17:360-7.

61. Wang H, Olivero W, Lanzino G, Elkins W, Rose J, Honings D, Rodde M, Burnham J, Wang D. Rapid and selective cerebral hypothermia achieved using a cooling helmet. J Neurosurg. 2004;100:272-7.

62. Busch HJ, Eichwede F, Födisch M, Taccone FS, Wöbker G, SchwabT, Hopf HB, Tonner P, Hachimi-Idrissi S, Martens P, Fritz H, Bode Ch, Vincent $J$, Inderbitzen B, Barbut D, Sterz F, Janata A. Safety and feasibility of nasopharyngeal evaporative cooling in the emergency department setting in survivors of cardiac arrest. Resuscitation. 2010;81:943-9.

63. Castrén M, Nordberg P, Svensson L, Taccone F, Vincent JL, Desruelles D, Eichwede F, Mols P, Schwab T, Vergnion M, Storm C, Pesenti A, Pachl J, Guérisse F, Elste T, Roessler M, Fritz H, Durnez P, Busch HJ, Inderbitzen $B$, Barbut D. Intra-arrest transnasal evaporative cooling: a randomized, prehospital, multicenter study (PRINCE: Pre-ROSC IntraNasal Cooling Effectiveness). Circulation. 2010;122:729-36. 
64. Fagnoul D, Taccone FS, Belhaj A, Rondelet B, Argacha JF, Vincent $J$ L, De Backer D. Extracorporeal life support associated with hypothermia and normoxemia in refractory cardiac arrest. Resuscitation. 2013;84:1519-24.

65. Laurent I, Adrie C, Vinsonneau C, Cariou A, Chiche JD, Ohanessian A, Spaulding C, Carli P, Dhainaut JF, Monchi M. High-volume hemofiltration after out-of-hospital cardiac arrest: a randomized study. J Am Coll Cardiol. 2005;46:432-7.

66. de Waard MC, Biermann H, Brinckman SL, Appelman YE, Driessen RH, Polderman KH, Girbes AR, Beishuizen A. Automated peritoneal lavage: an extremely rapid and safe way to induce hypothermia in post-resuscitation patients. Crit Care. 2013;17:R31.

67. Tømte $\varnothing$, Drægni T, Mangschau A, Jacobsen D, Auestad B, Sunde K. A comparison of intravascular and surface cooling techniques in comatose cardiac arrest survivors. Crit Care Med. 2011;39:443-9.

68. Holzer M, Müllner M, Sterz F, Robak O, Kliegel A, Losert H, Sodeck G, Uray T, Zeiner A, Laggner AN. Efficacy and safety of endovascular cooling after cardiac arrest: cohort study and Bayesian approach. Stroke. 2006;37:1792-7

69. Rana M, Schröder JW, Saygili E, Hameed U, Benke D, Hoffmann R, Schauerte P, Marx N, Rana OR. Comparative evaluation of the usability of 2 different methods to perform mild hypothermia in patients with out-of-hospital cardiac arrest. Int J Cardiol. 2011;152:321-6.

70. Våga A, Busch M, Karlsen TE, Nilsen OB, Søreide E. A pilot study of key nursing aspects with different cooling methods and devices in the ICU. Resuscitation. 2008;76:25-30.

71. Suh GJ, Kwon WY, Kim KS, Lee HJ, Jeong KY, Jung YS, Lee JH. Prolonged therapeutic hypothermia is more effective in attenuating brain apoptosis in a swine cardiac arrest model. Crit Care Med. 2014;42:e132-42.

72. Morrisson LJ, Deakin CD, Morley PT, Callaway CW, Kerber RE, Kronick SL, Lavonas EJ, Link MS, Neumar RW, Otto CW, Parr M, Shuster M, Sunde K, Peberdy MA, Tang W, VandenHoek TL, Böttiger BW, Drajer S, Lim HS, Nolan JP, Advanced Life Support Chapter Collaborators. Part 8: Advanced Life Support: 2010 International Consensus on Cardiopulmonary Resuscitation and Emergency Cardiovascular Care Science With Treatment Recommendations. Circulation. 2010;122:S345-421.

73. Nunnally ME, Jaeschke R, Bellingan GJ, Lacroix J, Mourvillier B, Rodriguez-Vega GM, Rubertsson S, Vassilakopoulos T, Weinert C, Zanotti-Cavazzoni S, Buchman TG. Targeted temperature management in critical care: a report and recommendations from five professional societies. Crit Care Med. 2011;39:1113-25.

74. Deye N, Arrich J, Cariou A. To cool or not to cool non-shockable CA patients: it is time for randomized controlled trials. Intensive Care Med. 2013;39:966-9.

75. Bougouin W, Lamhaut L, Marijon E, Jost D, Deye N, Chazelle E, Dumas $F$, Jouven $X$, Cariou A for the CEMS investigators. Characteristics and prognosis of sudden cardiac death in Greater Paris: population-based approach from the Paris Sudden Death Expertise Center. Intensive Care Med. 2014:40:846-54.

76. Nielsen N, Hovdenes J, Nilsson F, Rubertsson S, Stammet P, Sunde K, Valsson F, Wanscher M, Friberg H, Hypothermia Network. Outcome, timing and adverse events in therapeutic hypothermia after out-ofhospital cardiac arrest. Acta Anaesthesiol Scand. 2009;53:926-34.

77. Dumas F, Rea TD. Long term prognosis following resuscitation from OHCA: role of aetiology and presenting arrest rhythm. Resuscitation. 2012;83:1001-5

78. Jacobs SE, Berg M, Hunt R, Tarnow-Mordi WO, Inder TE, Davis PG. Cooling for newborns with hypoxic-ischemic encephalopathy (Review). Cochrane Database Syst Rev. 2013;1:CD003311.

79. Geurts M, Macleod MR, Kollmar R, Kremer PH, van der Worp HB. Therapeutic hypothermia and the risk of infection: a systematic review and meta-analysis. Crit Care Med. 2014;42:231-42.

80. Vaahersalo J, Hiltunen P, Tiainen M, Oksanen T, Kaukonen KM, Kurola J, Ruokonen E, Tenhunen J, Ala-Kokko T, Lund V, Reinikainen M, Kiviniemi O, Silfvast T, Kuisma M, Varpula T, Pettilä V, The FINNRESUSCI Study Group. Therapeutic hypothermia after out-of-hospital cardiac arrest in Finnish Intensive Care Units: the FINNRESUSCI Study. Intensive Care Med. 2013:39:826-37.

81. Pfeifer R, Jung C, Purle S, Lauten A, Yilmaz L, Surber R, Ferrari M, Figulla $H R$. Survival does not improve when therapeutic hypothermia is added to post-cardiac care. Resuscitation. 2011:82:1168-73.
82. Mader TJ, Nathanson BH, Soares WE, Coute RA, McNally BF. Comparative effectiveness of therapeutic hypothermia after out-of-hospital cardiac arrest: insight from a large data registry. Ther Hypothermia Temp Manag. 2014;4:21-31.

83. Lindner TW, Langorgen J, Sunde K, Larsen Al, Kvaloy JT, Heltne JK, Draegni T, Soreide E. Factors predicting the use of TH and survival in unconscious out-of-hospital cardiac arrest patients admitted to the ICU. Crit Care. 2013;17:R147.

84. Lee BH, Inui D, Suh GY, Kim JY, Kwon JY, Park J, Tada K, Tanaka K, letsugu K, Uehara K, Dote K, Tajimi K, Morita K, Matsuo K, Hoshino K, Hosokawa K, Lee KH, Lee KM, Takatori M, Nishimura M, Sanui M, Ito M, Egi M, Honda N, Okayama N, Shime N, Tsuruta R, Nogami S, Yoon SH, Fujitani S, Koh SO, Takeda S, Saito S, Hong SJ, Yamamoto T, Yokoyama T, Yamaguchi T, Nishiyama T, Igarashi T, Kakihana Y, Koh Y. The Fever and Antipyretic in Critically ill patients Evaluation (FACE) Study Group. Crit Care. 2012;16:R33

85. Gebhardt K, Guyette FX, Doshi AA, Callaway CW, Rittenberger JC, The Post CA Service. Prevalence and effect of fever on outcome following resuscitation from CA. Resuscitation. 2013;84:1062-7.

86. Nielsen N, Wetterslev J, Cronberg T, Erlinge D, Gasche Y, Hassager C, Horn J, Hovdenes J, Kjaergaard J, Kuiper M, Pellis T, Stammet P, Wanscher M, Wise MP, Åneman A, Al-Subaie N, Boesgaard S, Bro-Jeppesen J, Brunetti I, Bugge JF, Hingston CD, Juffermans NP, Koopmans M, Køber L, Langørgen J, Lilja G, Møller JE, Rundgren M, Rylander C, Smid O, Werer C, Winkel P, Friberg $\mathrm{H}$, TTM Trial Investigators. Targeted temperature management at $33^{\circ} \mathrm{C}$ versus $36^{\circ} \mathrm{C}$ after cardiac arrest. N Engl J Med. 2013;369:2197-206

87. Nielsen N, Sunde K, Hovdenes J, Riker RR, Rubertsson S, Stammet P, Nilsson F, Friberg H, Hypothermia Network. Adverse events and their relation to mortality in out-of-hospital cardiac arrest patients treated with therapeutic hypothermia. Crit Care Med. 2011;39:57-64.

88. Arrich J, Holzer M, Havel C, Müllner M, Herkner H. Hypothermia for neuroprotection in adults after cardiopulmonary resuscitation. Cochrane Database Syst Rev. 2012;9:CD004128.

89. Cueni-Villoz N, Devigili A, Delodder F, Cianferoni S, Feihl F, Rossetti AO, Eggimann P, Vincent JL, Taccone FS, Oddo M. Increased blood glucose variability during therapeutic hypothermia and outcome after cardiac arrest. Crit Care Med. 2011;39:2225-31.

90. Daviaud F, Dumas F, Demars N, Geri G, Bouglé A, Morichau-Beauchant T, Nguyen YL, Bougouin W, Pène F, Charpentier J, Cariou A. Blood glucose level and outcome after cardiac arrest: insights from a large registry in the hypothermia era. Intensive Care Med. 2014;40:855-62

91. Hypothermia after Cardiac Arrest Study G. Mild therapeutic hypothermia to improve the neurologic outcome after cardiac arrest. N Engl J Med. 2002;346:549-56.

92. Nielsen N, Friberg H, Gluud C, Herlitz J, Wetterslev J. Hypothermia after cardiac arrest should be further evaluated - a systematic review of randomised trials with meta-analysis and trial sequential analysis. Int J Cardiol. 2011;151:333-41.

93. Nielsen N, Wetterslev J, Al-Subaie N, Andersson B, Bro-Jeppesen J, Bishop G, Brunetti I, Cranshaw J, Cronberg T, Edqvist K, Erlinge D, Gasche Y, Glover G, Hassager C, Horn J, Hovdenes J, Johnsson J, Kjaergaard J, Kuiper M, Langorgen J, Macken L, Martinell L, Martner P, Pellis T, Pelosi P, Petersen P, Persson S, Rundgren M, Saxena M, Svensson R, Stammet P, Thoren A, Unden J, Walden A, Wallskog J, Wanscher M, Wise MP, Wyon N, Aneman A, Friberg H. Target temperature management after out-of-hospital cardiac arrest-a randomized, parallelgroup, assessor-blinded clinical trial-rationale and design. Am Heart J. 2012;163:541-8.

94. Nielsen N, Winkel P, Cronberg T, Erlinge D, Friberg H, Gasche Y, Hassager C, Horn J, Hovdenes J, Kjaergaard J, Kuiper M, Pellis T, Stammet P, Wanscher M, Wise MP, Aneman A, Wetterslev J. Detailed statistical analysis plan for the target temperature management after out-of-hospital cardiac arrest trial. Trials. 2013;14:300

95. Annborn M, Bro-Jeppesen J, Nielsen N, Ullen S, Kjaergaard J, Hassager C, Wanscher M, Hovdenes J, Pellis T, Pelosi P, Wise MP, Cronberg T, Erlinge $D$, Friberg $H$. The TTMti: the association of targeted temperature management at 33 and 36 degrees $C$ with outcome in patients with moderate shock on admission after out-of-hospital cardiac arrest: a post hoc analysis of the Target Temperature Management trial. Intensive Care Med. 2014:40:1210-9. 
96. Polderman KH. Mechanisms of action, physiological effects, and complications of hypothermia. Crit Care Med. 2009;37:S186-202.

97. Roberts BW, Kilgannon JH, Chansky ME, Mittal N, Wooden J, Trzeciak S. Association between postresuscitation partial pressure of arterial carbon dioxide and neurological outcome in patients with post-cardiac arrest syndrome: clinical perspective. Circulation. 2013;127:2107-13.

98. Kilgannon JH, Jones AE, Shapiro NI, Angelos MG, Milcarek B, Hunter K, Parrillo JE, Trzeciak S, Emergency Medicine Shock Research Network (EMShockNet) Investigators. Association between arterial hyperoxia following resuscitation from cardiac arrest and in-hospital mortality. JAMA. 2010;303:2165-71.

99. Wang $\mathrm{CH}$, Chang WT, Huang CH, Tsai MS, Yu PH, Wang AY, Chen NC, Chen WJ. The effect of hyperoxia on survival following adult cardiac arrest: a systematic review and meta-analysis of observational studies. Resuscitation. 2014;85:1142-8.

100. Sandroni C, D'Arrigo S. Management of oxygen and carbon dioxide pressure after cardiac arrest. Minerva Anestesiol. 2014;80:1-10.

101. Cornet AD, Kooter AJ, Peters MJL, Smulders YM. The potential harm of oxygen therapy in medical emergencies. Crit Care. 2013;17:313.

102. Yeh ST, Aune SE, Wilgus TA, Parent AE, Angelos MG. Hyperoxemic reperfusion after prolonged cardiac arrest in a rat cardiopulmonary bypass resuscitation model. Resuscitation. 2013;84:11-120.

103. Pilcher J, Weatherall M, Shirtcliffe P, Bellomo R, Young P, Beasley R. The effect of hyperoxia following cardiac arrest-a systematic review and meta-analysis of animal trials. Resuscitation. 2012;83:417-22.

104. Spindelboeck W, Schindler O, Moser A, Hausler F, Wallner S, Strasser C, Haas J, Gemes G, Prause G. Increasing arterial oxygen partial pressure during cardiopulmonary resuscitation is associated with improved rates of hospital admission. Resuscitation. 2013;84:770-5.

105. Kuisma M, Boyd J, Voipio V, Alaspää A, Roine RO, Rosenberg P. Comparison of 30 and the $100 \%$ inspired oxygen concentrations during early post-resuscitation period: a randomised controlled pilot study. Resuscitation. 2006;69:199-206.

106. Lee BK, Jeung KW, Lee HY, Lee SJ, Jung YH, Lee WK, Heo T, Min YI. Association between mean arterial oxygen blood gas tension and outcome in cardiac arrest patients treated with therapeutic hypothermia. Am J Emerg Med. 2014;32:55-60.

107. Vaahersalo J, Bendel S, Reinikainen M, Kurola J, Tiainen M, Raj R, Pettilä V, Varpula T, Skrifvars MB, FINNRESUSCI Study Group. Arterial blood gas tensions after resuscitation from out-of-hospital cardiac arrest: associations with long-term neurologic outcome. Crit Care Med. 2014;42:1463-70.

108. Voicu S, Deye N, Malissin I, Vigué B, Brun PY, Haik W, Champion S, Megarbane B, Sideris G, Mebazaa A, Carli P, Manivet P, Baud FJ. Influence of $\alpha$-stat and $\mathrm{pH}$-stat blood gas management strategies on cerebral blood flow and oxygenation in patients treated with therapeutic hypothermia after out-of-hospital cardiac arrest: a crossover study. Crit Care Med. 2014;42:1849-61.

109. Schneider AG, Eastwood GM, Bellomo R, Bailey M, Lipcsey M, Pilcher D, Young P, Stow P, Santamaria J, Stachowski E, Suzuki S, Woinarski NC, Pilcher J. Arterial carbon dioxide tension and outcome in patients admitted to the intensive care unit after cardiac arrest. Resuscitation. 2013;84:927-34.

110. Roberts BW, Kilgannon JH, Chansky ME, Trzeciak S. Association between initial prescribed minute ventilation and post-resuscitation partial pressure of arterial carbon dioxide in patients with post-cardiac arrest syndrome. Ann Intensive Care. 2014;4:9.

111. Dell'Anna AM, Scolletta S, Donadello K, Taccone FS. Early neuroprotection after cardiac arrest. Curr Opin Crit Care. 2014;20:250-8.

112. Wiklund L, Martijn C, Miclescu A, Semenas E, Rubertsson S, Sharma HS. Central nervous tissue damage after hypoxia and reperfusion in conjunction with cardiac arrest and cardiopulmonary resuscitation: mechanisms of action and possibilities for mitigation. Int Rev Neurobiol. 2012;02:173-87.

113. Mangus DB, Huang L, Applegate PM, Gatling JW, Zhang J, Applegate $\mathrm{RL}$ 2nd. A systematic review of neuroprotective strategies after cardiac arrest: from bench to bedside (Part I_protection via specific pathways). Med Gas Res. 2014;4:9.

114. Thel MC, Armstrong AL, McNulty SE, Califf RM, O'Connor CM. Randomised trial of magnesium in in-hospital cardiac arrest. Duke Internal Medicine Housestaff. Lancet. 1997;350:1272-6.
115. Longstreth WT Jr, Fahrenbruch CE, Olsufka M, Walsh TR, Copass MK, Cobb LA. Randomized clinical trial of magnesium, diazepam, or both after out-of-hospital cardiac arrest. Neurology. 2002;59:506-14.

116. Meloni BP, Campbell K, Zhu H, Knuckey NW. In search of clinical neuroprotection after brain ischemia: the case for mild hypothermia (35 degrees C) and magnesium. Stroke. 2009;40:2236-40.

117. Dorhout Mees SM, Algra A, Vandertop WP, van Kooten F, Kuijsten HA, Boiten J, van Oostenbrugge RJ, Al-Shahi Salman R, Lavados PM, Rinkel GJ, van den Bergh WM, MASH-2 Study Group. Magnesium for aneurysmal subarachnoid haemorrhage (MASH-2): a randomised placebocontrolled trial. Lancet. 2012;380:44-9.

118. Temkin NR, Anderson GD, Winn HR, Ellenbogen RG, Britz GW, Schuster J, Lucas T, Newell DW, Mansfield PN, Machamer JE, Barber J, Dikmen SS. Magnesium sulfate for neuroprotection after traumatic brain injury: a randomised controlled trial. Lancet Neurol. 2007;6:29-38.

119. Schmidt M, Marx T, Gloggl E, Reinelt H, Schirmer U. Xenon attenuates cerebral damage after ischemia in pigs. Anesthesiology. 2005;102:929-36.

120. Brucken A, Cizen A, Fera C, Meinhardt A, Weis J, Nolte K, Rossaint R, Pufe T, Marx G, Fries M. Argon reduces neurohistopathological damage and preserves functional recovery after cardiac arrest in rats. Br J Anaesth. 2013;110:1106-12.

121. Arola OJ, Laitio RM, Roine RO, Grönlund J, Saraste A, Pietilä M, Airaksinen J, Perttilä J, Scheinin H, Olkkola KT, Maze M, Laitio TT. Feasibility and cardiac safety of inhaled xenon in combination with therapeutic hypothermia following out-of-hospital cardiac arrest. Crit Care Med. 2013;41:2116-24.

122. Ruscher K, Freyer D, Karsch M, Isaev N, Megow D, Sawitzki B, Priller J, Dirnagl U, Meisel A. Erythropoietin is a paracrine mediator of ischemic tolerance in the brain: evidence from an in vitro model. J Neurosci. 2002;22:10291-301.

123. Borovnik-Lesjak V, Whitehouse K, Baetiong A, Artin B, Radhakrishnan J, Gazmuri RJ. High-dose erythropoietin during cardiac resuscitation lessens postresuscitation myocardial stunning in swine. Transl Res. 2013;162:110-21.

124. Unden J, Sjolund C, Lansberg JK, Wieloch T, Ruscher K. Romner B Postischemic continuous infusion of erythropoietin enhances recovery of lost memory function after global cerebral ischemia in the rat. BMC Neurosci. 2013;14:27.

125. Grmec S, Strnad M, Kupnik D, Sinkovic A, Gazmuri RJ. Erythropoietin facilitates the return of spontaneous circulation and survival in victims of out-of-hospital cardiac arrest. Resuscitation. 2009;80:631-7.

126. Cariou A, Claessens YE, Pene F, Marx JS, Spaulding C, Hababou C, Casadevall N, Mira JP, Carli P, Hermine O. Early high-dose erythropoietin therapy and hypothermia after out-of-hospital cardiac arrest: a matched control study. Resuscitation. 2008;76:397-404.

127. Elrod JW, Molkentin JD. Physiologic functions of cyclophilin D and the mitochondrial permeability transition pore. Circ J. 2013;77:1111-22.

128. Huang CH, Tsai MS, Hsu CY, Su YJ, Wang TD, Chang WT, Chen WJ. Postcardiac arrest myocardial dysfunction is improved with cyclosporine treatment at onset of resuscitation but not in the reperfusion phase. Resuscitation. 2011;82:S41-7.

129. Piot C, Croisille P, Staat P, Thibault H, Rioufol G, Mewton N, Elbelghiti R, Cung TT, Bonnefoy E, Angoulvant D, Macia C, Raczka F, Sportouch C, Gahide G, Finet G, André-Fouët X, Revel D, Kirkorian G, Monassier JP, Derumeaux G, Ovize M. Effect of cyclosporine on reperfusion injury in acute myocardial infarction. N Engl J Med. 2008;359:473-81.

130. Kohr MJ, Sun J, Aponte A, Wang G, Gucek M, Murphy E, Steenbergen C. Simultaneous measurement of protein oxidation and S-nitrosylation during preconditioning and ischemia/reperfusion injury with resinassisted capture. Circ Res. 2011;108:418-26.

131. Dezfulian C, Shiva S, Alekseyenko A, Pendyal A, Beiser DG, Munasinghe JP, Anderson SA, Chesley CF, Vanden Hoek TL, Gladwin MT. Nitrite therapy after cardiac arrest reduces reactive oxygen species generation, improves cardiac and neurological function, and enhances survival via reversible inhibition of mitochondrial complex I. Circulation. 2009;120:897-905.

132. Minamishima S, Kida K, Tokuda K, Wang H, Sips PY, Kosugi S, Mandeville JB, Buys ES, Brouckaert P, Liu PK, Liu CH, Bloch KD, Ichinose F. Inhaled nitric oxide improves outcomes after successful cardiopulmonary resuscitation in mice. Circulation. 2011;124:1645-53. 
133. Dezfulian C, Alekseyenko A, Dave KR, Raval AP, Do R, Kim F, Perez-Pinzon MA. Nitrite therapy is neuroprotective and safe in cardiac arrest survivors. Nitric Oxide. 2012;26:241-50.

134. Mentzelopoulos SD, Malachias S, Chamos C, Konstantopoulos D, Ntaidou T, Papastylianou A, Kolliantzaki I, Theodoridi M, Ischaki H, Makris D, Zakynthinos E, Zintzaras E, Sourlas S, Aloizos S, Zakynthinos SG. Vasopressin, steroids, and epinephrine and neurologically favorable survival after in-hospital cardiac arrest: a randomized clinical trial. JAMA. 2013;310:270-9.

135. Pene F, Hyvernat H, Mallet V, Cariou A, Carli P, Spaulding C, Dugue MA, Mira JP. Prognostic value of relative adrenal insufficiency after out-ofhospital cardiac arrest. Intensive Care Med. 2005;31:627-33.

136. Donadello K, Favory R, Salgado-Ribeiro D, Vincent JL, Gottin L, Scolletta S, Creteur J, De Backer D, Taccone FS. Sublingual and muscular microcirculatory alterations after cardiac arrest: a pilot study. Resuscitation. 2011;82:690-5.

137. Laureys S, Owen AM, Schiff ND. Brain function in coma, vegetative state, and related disorders. Lancet Neurol. 2004;3:537-46.

138. Laureys S. Science and society: death, unconsciousness and the brain. Nat Rev Neurosci. 2005;6:899-909.

139. Laureys S, Celesia GG, Cohadon F, Lavrijsen J, León-Carrión J, Sannita WG, Sazbon L, Schmutzhard E, von Wild KR, Zeman A, Dolce G. Unresponsive wakefulness syndrome: a new name for the vegetative state or apallic syndrome. European Task Force on Disorders of Consciousness. BMC Med. 2010;8:68.

140. Giacino JT, Fins JJ, Laureys S, Schiff ND. Disorders of consciousness after acquired brain injury: the state of the science. Nat Rev Neurol. 2014;10:99-114.

141. Bruno MA, Vanhaudenhuyse A, Thibaut A, Moonen G, Laureys S. From unresponsive wakefulness to minimally conscious PLUS and functional locked-in syndromes: recent advances in our understanding of disorders of consciousness. J Neurol. 2011;258:1373.

142. Noirhomme Q, Lehembre R, Lugo Zdel R, Lesenfants D, Luxen A, Laureys S, Oddo M, Rossetti AO. Automated analysis of background EEG and reactivity during therapeutic hypothermia in comatose patients after cardiac arrest. Clin EEG Neurosci. 2014;45:6-13.

143. Casali AG, Gosseries O, Rosanova M, Boly M, Sarasso S, Casali KR, Casarotto S, Bruno MA, Laureys S, Tononi G, Massimini M. A theoretically based index of consciousness independent of sensory processing and behavior. Sci Transl Med. 2013;5:198ra105.

144. Ma Y, Fei Z, Qu Y. Willful modulation of brain activity in disorders of consciousness. N Engl J Med. 2010;362:579-89.

145. Laureys S, Schiff ND. Coma and consciousness: paradigms (re)framed by neuroimaging. Neuroimage. 2012;61:478-91.

146. Luyt CE, Galanaud D, Perlbarg V, Vanhaudenhuyse A, Stevens RD, Gupta R, Besancenot H, Krainik A, Audibert G, Combes A, Chastre J, Benali H, Laureys S, Puybasset L. Diffusion tensor imaging to predict long-term outcome after cardiac arrest: a bicentric pilot study. Neuro Imaging for Coma Emergence and Recovery Consortium. Anesthesiology. 2012;117:1311-21.

147. Stender J, Gosseries O, Bruno MA, Charland-Verville V, Vanhaudenhuyse A, Demertzi A, Chatelle C, Thonnard M, Thibaut A, Heine L, Soddu A, Boly M, Schnakers C, Gjedde A, Laureys S. Diagnostic precision of PET imaging and functional MRI in disorders of consciousness: a clinical validation study. Lancet. 2014;384:514-22.

148. Gosseries O, Charland-Verville V, Thonnard M, Bodart O, Laureys S, Demertzi A. Amantadine, apomorphine and zolpidem in the treatment of disorders of consciousness. Curr Pharm Des. 2014;20:4167-84.

149. Thibaut A, Bruno MA, Ledoux D, Demertzi A, Laureys S. tDCS in patients with disorders of consciousness: sham-controlled randomized doubleblind study. Neurology. 2014;82:1112-8.

150. Chatelle C, Majerus S, Whyte J, Laureys S, Schnakers C. A sensitive scale to assess nociceptive pain in patients with disorders of consciousness. J Neurol Neurosurg Psychiatry. 2012;83:1233-7.

151. Jox RJ, Bernat JL, Laureys S, Racine E. Disorders of consciousness: responding to requests for novel diagnostic and therapeutic interventions. Lancet Neurol. 2012;11:732-8.

152. Demertzi A, Ledoux D, Bruno MA, Vanhaudenhuyse A, Gosseries O, Soddu A, Schnakers C, Moonen G, Laureys S. Attitudes towards end-oflife issues in disorders of consciousness: a European survey. J Neurol. 2011:258(6):1058-65.
153. Taccone FS, Cronberg T, Friberg H, Greer D, Horn J, Oddo M, Scolletta S, Vincent JL. How to assess prognosis after cardiac arrest and therapeutic hypothermia. Crit Care. 2014;18:202.

154. Samaniego EA, Mlynash M, Caulfield AF, Eyngorn I, Wijman CA. Sedation confounds outcome prediction in cardiac arrest survivors treated with hypothermia. Neurocrit Care. 2011;15:113-9.

155. Kamps MJ, Horn J, Oddo M, Fugate JE, Storm C, Cronberg T, Wijman CA, Wu O, Binnekade JM, Hoedemaekers CW. Prognostication of neurologic outcome in cardiac arrest patients after mild therapeutic hypothermia: a meta-analysis of the current literature. Intensive Care Med. 2013;39:1671-82.

156. Sandroni C, Cavallaro F, Callaway CW, D’Arrigo S, Sanna T, Kuiper MA, Biancone M, Della Marca G, Farcomeni A, Nolan JP. Predictors of poor neurological outcome in adult comatose survivors of cardiac arrest: a systematic review and meta-analysis. Part 2: patients treated with therapeutic hypothermia. Resuscitation. 2013;84:1324-38.

157. Suys T, Bouzat P, Marques-Vidal P, Sala N, Payen JF, Rossetti AO, Oddo M. Automated quantitative pupillometry for the prognostication of coma after cardiac arrest. Neurocrit Care. 2014;21:300-8.

158. Greer DM, Yang J, Scripko PD, Sims JR, Cash S, Wu O, Hafler JP, Schoenfeld DA, Furie KL. Clinical examination for prognostication in comatose cardiac arrest patients. Resuscitation. 2013;84:1546-51.

159. Oddo M, Rossetti AO. Early multimodal outcome prediction after cardiac arrest in patients treated with hypothermia. Crit Care Med. 2014:42:1340-7

160. Ben-Hamouda N, Taccone FS, Rossetti AO, Oddo M. Contemporary approach to neurologic prognostication of coma after cardiac arrest. Chest. 2014;146:1375-86.

161. Friberg H, Rundgren M, Westhall E, Nielsen N, Cronberg T. Continuous evaluation of neurological prognosis after cardiac arrest. Acta Anaesthesiol Scand. 2013;57:6-15.

162. Hirsch LJ, LaRoche SM, Gaspard N, Gerard E, Svoronos A, Herman ST, Mani R, Arif H, Jette N, Minazad Y, Kerrigan JF, Vespa P, Hantus S, Claassen J, Young GB, So E, Kaplan PW, Nuwer MR, Fountain NB, Drislane FW. American Clinical Neurophysiology Society's Standardized Critical Care EEG Terminology: 2012 version. J Clin Neurophysiol. 2013;30:1-27.

163. Wijdicks EF, Hijdra A, Young GB, Bassetti CL, Wiebe S, Quality Standards Subcommittee of the American Academy of N. Practice parameter: prediction of outcome in comatose survivors after cardiopulmonary resuscitation (an evidence-based review): report of the Quality Standards Subcommittee of the American Academy of Neurology. Neurology. 2006;67:203-10.

164. Rossetti AO, Oddo M, Logroscino G, Kaplan PW. Prognostication after cardiac arrest and hypothermia: a prospective study. Ann Neurol. 2010;67:301-7.

165. Friedman D, Claassen J, Hirsch LJ. Continuous electroencephalogram monitoring in the intensive care unit. Anesth Analg. 2009;109:506-23.

166. Friberg $\mathrm{H}$, Westhall $\mathrm{E}$, Rosen I, Rundgren M, Nielsen N, Cronberg T. Clinical review: continuous and simplified electroencephalography to monitor brain recovery after cardiac arrest. Crit Care. 2013;17:233.

167. Rundgren M, Westhall E, Cronberg T, Rosen I, Friberg H. Continuous amplitude-integrated electroencephalogram predicts outcome in hypothermia-treated cardiac arrest patients. Crit Care Med. 2010;38:1838-44.

168. Cronberg $\mathrm{T}$, Westhall $\mathrm{E}$, Friberg $\mathrm{H}$. Is continuous EEG-monitoring value for money for cardiac arrest patients in the intensive care unit? Resuscitation. 2014;85:716-7.

169. Moulaert VR, Verbunt JA, van Heugten CM, Wade DT. Cognitive impairments in survivors of out-of-hospital cardiac arrest: a systematic review. Resuscitation. 2009;80:297-305.

170. Neumar RW, Nolan JP, Adrie C, Aibiki M, Berg RA, Böttiger BW, Callaway C, Clark RS, Geocadin RG, Jauch EC, Kern KB, Laurent I, Longstreth WT $J$ r, Merchant RM, Morley P, Morrison LJ, Nadkarni V, Peberdy MA, Rivers EP, Rodriguez-Nunez A, Sellke FW, Spaulding C, Sunde K, Vanden Hoek T. Post-cardiac arrest syndrome: epidemiology, pathophysiology, treatment, and prognostication. A consensus statement from the International Liaison Committee on Resuscitation (American Heart Association, Australian and New Zealand Council on Resuscitation, European Resuscitation Council, Heart and Stroke Foundation of Canada, InterAmerican Heart Foundation, Resuscitation Council of Asia, and the Resuscitation Council of Southern Africa); the American Heart Association Emergency 
Cardiovascular Care Committee; the Council on Cardiovascular Surgery and Anesthesia; the Council on Cardiopulmonary, Perioperative, and Critical Care; the Council on Clinical Cardiology; and the Stroke Council. Circulation. 2008;118:2452-83.

171. World Health Organization. How to use the ICF: a practical manual for using the International Classification of Functioning, Disability and Health (ICF). Geneva: WHO. Exposure draft for comment. 2013. http:// www.who.int/classifications/drafticfpracticalmanual.pdf.

172. Kucukdeveci AA, Tennant A, Grimby G, Franchignoni F. Strategies for assessment and outcome measurement in physical and rehabilitation medicine: an educational review. J Rehabil Med. 2011;43:661-72.

173. American Academy of Clinical Neuropsychology. Neuropsychology model LCD taskforce. 2011. http://www.theaacn.org/userdocuments/ neuropsychology_model_lcd-1.pdf.

174. Rossetti AO, Logroscino G, Liaudet L, Ruffieux C, Ribordy V, Schaller MD, Despland PA, Oddo M. Status epilepticus: an independent outcome predictor after cerebral anoxia. Neurology. 2007;69:255-60.

175. Legriel S, Hilly-Ginoux J, Resche-Rigon M, Merceron S, Pinoteau J, Henry-Lagarrigue M, Bruneel F, Nguyen A, Guezennec P, Troché G, Richard O, Pico F, Bédos JP. Prognostic value of electrographic postanoxic status epilepticus in comatose cardiac-arrest survivors in the therapeutic hypothermia era. Resuscitation. 2013;84:343-50.
176. Claassen J, Taccone FS, Horn P, Holtkamp M, Stocchetti N, Oddo M. Recommendations on the use of EEG monitoring in critically ill patients: consensus statement from the neurointensive care section of the ESICM. Intensive Care Med. 2013;39:1337-51.

177. Puybasset L, Bazin JE, Beloucif S, Bizouarn P, Crozier S, Devalois B, Eon B, Fieux F, Gisquet E, Guibet-Lafaye C, Kentish N, Lienhart A, NicolasRobin A, Otero Lopez M, Pelluchon C, Roussin F, Beydon L, Sfar (Comite d'éthique ICARE). Critical appraisal of organ procurement under Maastricht 3 condition. Ann Fr Anesth Rean. 2014;33:102-27.

178. Graftieaux JP, Bollaert P-E, Haddad L, Kentish-Barnes N, Nitenberg G, Robert R, Villers D, Dreyfuss D, ethics committee of the SRLF. Contribution of the ethics committee of the French society of intensive care to a scenario for the implementation of organ donation after Maastricht III-type cardiac death in France. Ann Fr Anesth Rean. 2014;33:128-34.

179. Wise MP, et al. Targeted temperature management after cardiac arrest: certainties and uncertainties. Crit Care. 2014;18:459.

\section{Submit your manuscript to a SpringerOpen ${ }^{\odot}$ journal and benefit from:}

- Convenient online submission

- Rigorous peer review

- Immediate publication on acceptance

- Open access: articles freely available online

- High visibility within the field

- Retaining the copyright to your article

Submit your next manuscript at $\boldsymbol{~ s p r i n g e r o p e n . c o m ~}$ 